\title{
FIV as a Model for AIDS Vaccine Studies
}

\author{
STEPHEN DUNHAM and OSWALD JARRETT
}

\section{INTRODUCTION}

Many experimental strategies have been adopted in experiments to protect cats from FIV infection by vaccination, and some have been successful. The interest in developing a vaccine arose both because FIV is a common cause of morbidity and mortality in pet cats and because the feline virus provides a model for its counterpart in man, human immunodeficiency virus (HIV), for which an effective vaccine is urgently required to halt the current tragic pandemic of acquired immunodeficiency syndrome (AIDS). Shortly after the discovery of FIV and its characterization as a lentivirus,${ }^{54}$ attempts were made to produce a vaccine and success was soon achieved with relatively simple inactivated virus or inactivated virus-infected cell vaccines ${ }^{82}$ Further development of this approach led to the introduction in 2002 of the first commercial vaccine against FIV. ${ }^{59}$ With an estimated prevalence of the infection of up to $25 \%$ in populations of pet cats, an effective FIV vaccine could have a significant influence on animal welfare. In addition, this success poses the question of whether a similar strategy might produce an effective vaccine against HIV.

Many candidate HIV vaccines have been constructed and a number are currently undergoing clinical trials in human populations. The results from the first phase III trial, which was designed to test the ability of a vaccine based on the envelope surface glycoprotein (SU) to protect against exposure to HIV in a high-risk population, were not encouraging. Much of the slow progress in producing HIV vaccines to take to phase III trials is because there is no ideal surrogate host in which to carry out experiments that would confidently predict whether a candidate vaccine was

STEPHEN DUNHAM AND OSWALD JARRETT - Retrovirus Research Laboratory, Institute of Comparative Medicine, University of Glasgow, Faculty of Veterinary Medicine, Bearsden Road, Glasgow G61 1QH, U.K. 
indeed protective or would identify the correlates of protection. Even in the chimpanzee, the putative source of the simian immunodeficiency virus (SIV) from which HIV was originally derived, the dynamics of experimental HIV infection are sufficiently different from those in man to render the model problematic. SIV itself is a plausible model system in which to test vaccine strategies and has been used extensively for this purpose as described in Chapters 5 and 6 . Although these simian viruses do not appear to cause disease in their natural hosts-various primate species in Africathey do cause a fatal immunodeficiency upon inoculation of Asian macaques that is very similar to human AIDS. This outcome may very well mimic the situation that has developed in man, who has yet to coevolve sufficiently with HIV to render that virus less pathogenic. Many SIV vaccines have been tested in macaques, but still there is no consensus about what constitutes a vaccine that could serve as an example for HIV. The apparent effectiveness of the recently introduced commercial FIV vaccine raises the questions of how good FIV is as a comparative model system for HIV in vaccination studies, and what weight should be put on the results from FIV vaccine trials in making decisions about the type of HIV vaccine to be tested in clinical trials in man.

In this review we examine the similarities between FIV and HIV that make the feline virus an excellent model with which to pursue vaccine strategies for human AIDS. We then discuss the crucial issues that must be considered and the choices that have to be made in producing FIV vaccines. Finally, we discuss the results of experimental trials of a selection of FIV vaccines that might influence the development of vaccines for HIV.

\section{RELEVANGE OF FIV TO HIV VACCINATION}

How similar are FIV and HIV? Certainly there are differences between the two viruses in biology and natural history. Thus, FIV has a different genome content and organization from HIV, as illustrated in Figure 1. In nature FIV is transmitted mainly by biting, rather than through a mucosal surface like HIV. Following infection, a proportion of infected cats develop AIDS, although many individuals do not develop terminal disease. ${ }^{1}$ To enter cells, primary isolates of FIV use CD134 as a receptor ${ }^{66}$ and CXCR4 as a coreceptor. ${ }^{78}$ In contrast HIV-1 uses CD4 as a primary receptor and CCR5 and other chemokine receptors, including CXCR4, as a coreceptor. However, despite these differences, both viruses critically target $\mathrm{CD} 4^{+} \mathrm{T}$ lymphocytes and the outcome of infection is remarkably similar in cats and man. In the present context, the dynamics of infection and the resulting immune response are so much alike following infection with either virus that FIV should be able to provide valuable information to aid the development of HIV vaccines. It is the common features of FIV and HIV rather 
Feline immunodeficiency virus genome

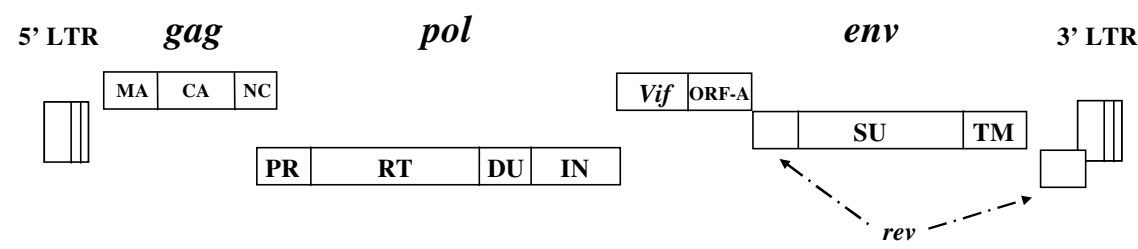

Human immunodeficiency virus (Type 1) genome

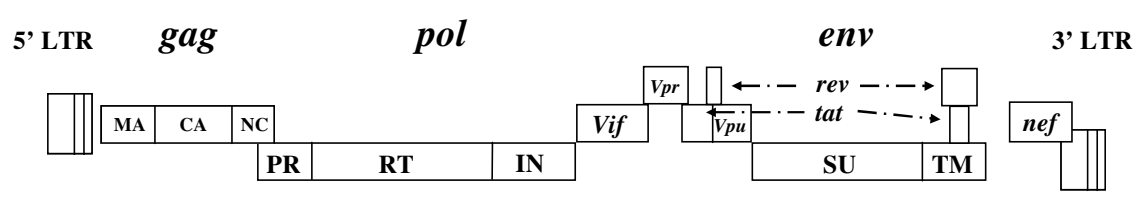

FIGURE 1. Comparison of FIV and HIV-1 genomes.

than their differences that should guide us to the essential requirements for successful protection by vaccination against each infection.

\section{The FIV Genome}

FIV, like HIV, is a complex retrovirus, with a genome approximately $10 \mathrm{~kb}$ in size, containing accessory genes in addition to gag, pol, and env (Figure 1). A comparison of the nucleotide sequences of representative FIV and HIV sequences (FIV Petaluma M25381 and HIV NC_001802) reveals an overall homology of approximately $63 \%$ in gag-pol and $76 \%$ in env. The corresponding proteins exhibit lower homology of $43 \%$ and $35 \%$ respectively (comparisons made using GCG Bestfit, University of Wisconsin). The feline pol gene, like HIV, encodes protease, integrase, and reverse transcriptase proteins, which have analogous functions in each of the viruses. FIV pol also encodes an additional enzyme, deoxyuridine pyrophosphatase (DU), not found in primate lentiviruses, which reduces cellular concentrations of dUTP, preventing viral mutations due to its misincorporation into viral cDNA. The activity of viral DU is particularly important in nondividing cells such as macrophages, which have low endogenous levels of the host enzyme. FIV mutants lacking DU are consequently unable to replicate productively in macrophages. ${ }^{40}$ Although DU is absent in HIV, its role is assumed by HIV Vpr, which directs incorporation of uracil DNA glycosylase (UNG2) into HIV virions, thereby reducing misincorporation of uracil and facilitating replication in macrophages. ${ }^{9}$ 
The export of unspliced and singly spliced viral RNAs from the nucleus requires the presence of Rev, which is encoded by both HIV and FIV genomes. Rev mediates nuclear export by binding to the Rev response element (RRE). For FIV the RRE is located $3^{\prime}$ to the transmembrane (TM) protein of Env, whereas in HIV the RRE is $5^{\prime}$ to TM. The vif (viral infectivity factor) gene is also common to both FIV and HIV and functions in a similar way for both viruses. Vif expression is critical for viral dissemination in vivo and infection of nonpermissive cells including lymphocytes and macrophages. Recent evidence has shown that HIV Vif acts by abrogating the effect of the cellular antiretroviral factor APOBEC3G,${ }^{65}$ and it is likely that FIV Vif acts in an analogous manner. FIV lacks a tat gene and its corresponding transactivation response (TAR) element. Additionally, the FIV genome does not encode Nef, Vpr, or Vpu. It does, however, encode an additional accessory protein designated ORF-A or ORF-2. ORF-A was initially considered as a tat-like gene because of its ability to transactivate viral transcription at low levels. However, it shares several properties with HIV Vpr, including nuclear localization and induction of G2 cell cycle arrest. $^{22}$

Knowledge of the genetic structure of FIV allows the use of virus mutants as experimental vaccines. For example, the deletion of accessory genes such as ORF-A or vif can result in the production of attenuated viruses that can be utilized as vaccines. ${ }^{43}$ DNA vaccines have also been produced using full-length molecular clones of provirus, which are rendered replication defective by in-frame deletion of either the reverse transcriptase or integrase genes. ${ }^{16,29}$

\section{FIV Infection in Cats}

Most natural FIV infections are acquired by biting, presumably through the inoculation of virus, or virus-infected cells, from the saliva of persistently infected cats. Cats are readily infected by parenteral inoculation of virus, for example, by the intravenous, intraperitoneal, or intramuscular route. Transmission from mother to her kittens may occur but only a proportion of the offspring become persistently infected. Although neither oronasal or venereal spread has been documented in nature, cats can be infected by experimental inoculation of virus into the nose, mouth, vagina, and rectum ${ }^{51}$ and the virus can be recovered from semen following natural or experimental infection. ${ }^{37}$ In each case, inoculation results in the infection of lymphoid and myelomonocytic cells, which become reservoirs that maintain a persistent infection.

FIV closely resembles HIV in the dynamics of its growth in vivo. Thus, in the first few days following experimental inoculation, the virus grows in 
dendritic cells, macrophages, and $\mathrm{CD} 4^{+} \mathrm{T}$ lymphocytes and is found in the plasma within 2 weeks. The level of virus in the plasma and proviral DNA in the blood mononuclear cells rises over a period, reaching a peak at about 8 to 12 weeks. During this period, mild to moderate clinical signs, for example anorexia, depression, and pyrexia, may be observed that are associated with the initial uninhibited growth of the virus. These conditions generally subside rapidly, although signs such as generalized lymphadenopathy, due to increased numbers and size of active germinal centers in the cortex of the lymph nodes, may continue for several weeks or months. The fall in plasma viral load heralds the beginning of the socalled asymptomatic phase that can last for many years, and in many cases for life, during which the cat is quite healthy. It is assumed that virus replication is brought under control by the developing immune response to the virus. CD8 ${ }^{+}$FIV-specific cytotoxic T-cells (CTL) can be detected in the blood within one week of infection. ${ }^{3}$ Rather later, at around the same time as the peak in virus load, anti-FIV antibodies, including virus neutralizing antibodies, appear in the plasma. ${ }^{17}$

Another hallmark of early FIV infection by certain isolates is the appearance of a population of $\mathrm{CD}^{+}{ }^{\mathrm{T}} \mathrm{T}$-cells termed $\mathrm{CD} 8^{\text {low }}$, 77 which has the phenotype $\alpha^{+} / \beta^{\text {low }}$. These cells serve as a marker of immune activation by more virulent strains of FIV and functionally may contribute to the noncytolytic activity for FIV mediated by $\mathrm{CD} 8^{+} \mathrm{T}$-cells.

The final outcome of FIV infection, following experimental or natural challenge, is variable. During the asymptomatic phase the plasma virus load is stable, but a progressive decline in $\mathrm{CD} 4^{+} \mathrm{T}$ lymphocyte numbers occurs. In an as yet unknown proportion of naturally infected cats, this decline results in a functional immunodeficiency that leads to clinical disease and death. In one experiment, in which cats were infected as kittens with the FIV-GL8 strain and were maintained for 10 years, approximately half of the cats developed serious and ultimately fatal conditions that could be ascribed to the infection (John Callanan, personal communication). By contrast, in a completely closed household of 26 pet cats observed over a 10-year period, natural FIV spread slowly among the cats but did not appear to cause any significant disease. ${ }^{1}$ Clearly, in vaccine trials with FIV or HIV, the efficacy of vaccination must be measured by the capacity of the vaccine to prevent infection rather than disease.

As discussed below in more detail, strains of FIV differ in virulence. Viruses of high virulence are defined here as those that establish high virus loads, cause a reduction in $\mathrm{CD}^{+} \mathrm{T}$ lymphocyte numbers, and activate $\mathrm{CD} 8^{\text {low }}$ T-cells. By contrast, viruses of low virulence establish infections so that plasma viral RNA and proviral DNA or infectious virus may be difficult to detect. These viruses do not cause a decline in $\mathrm{CD} 4^{+} \mathrm{T}$-cell numbers or induce a rise in $\mathrm{CD} 8^{\text {low }} \mathrm{T}$-cells. 


\section{Immune Responses to FIV Infection}

Although the immune response to natural or experimental FIV infection does not eliminate the virus from its host, as in HIV infection, it is sufficiently powerful to contain the infection for many years. Consequently, it is not unreasonable to believe that the quality of this response might be one to emulate by vaccination and that if the immune system is appropriately primed before exposure, that more effective control of the virus may be possible. As noted above, the responses that accompany FIV infection and are presumed to play a major role in inhibiting viral infection are the induction of CTL and virus neutralizing antibodies. Although our ability to define precisely the details of feline immune responses is fairly rudimentary because of a relative lack of reagents, compared to those available for man and macaques, there is in fact very little difference between FIV, SIV, and HIV in our understanding of the appropriate immune responses that block viral infection. Early studies on HIV vaccination concentrated on raising virus neutralizing antibodies and hence on generating vaccines that incorporated SU that contains the targets for these antibodies. It was considered desirable to include antigens that could induce antibodies that would neutralize viruses of as many clades of virus as possible. Later research concluded that CTL were crucial in protective immunity and several vaccine approaches have been developed, which include peptide epitopes recognized by appropriate haplotypes of populations in which the vaccine might be applied. This same cycle of opinion has occurred in FIV vaccine research.

\section{GRUCIAL FACTORS IN FIV VACCINE DEVELOPMENT STRATEGIES}

\section{Viral Immunogens}

An unresolved issue for both FIV and HIV is which virus strain or isolate should be used as a source of immunogen in a vaccine. There are a number of FIV strains that have been used as antigens or challenge viruses, including viruses with differences in antigenicity, clade, and virulence.

\section{Antigenic Variation}

A major consideration in the development of any vaccine is whether there is antigenic variation between virus isolates to which the target population might be exposed. With their high rates of mutation and recombination, together with the selection pressure applied by the antiviral 
immune responses of the host, lentiviruses might be expected to be highly antigenically variable; and so it has proved.

The classical method of antigenic typing of viruses is by virus neutralization. Unfortunately, as for HIV, the measurement of virus neutralizing antibodies against FIV has been, and remains, difficult. In early studies, neutralization by sera, from infected or vaccinated cats of FIV adapted for growth in the feline fibroblast cell line CRFK, was reported. ${ }^{17}$ However, this type of CRFK-tropic, and probably CD134-independent, FIV does not represent the majority of viruses that are isolated from naturally infected cats and are probably transmitted in the field (Hayley Haining and Margaret Hosie, personal communication). It is likely that neutralization of these viruses in this assay is mediated through blocking of the interaction between the V3 region of SU and CXCR4 by anti-V3 antibodies, as virus neutralizing antibodies can be completely absorbed by a peptide that represents the V3 loop (Robert Osborne, personal communication). Cats vaccinated with an inactivated virus vaccine that had high levels of virus neutralizing antibodies measured in this way were protected from challenge with the CRFK-tropic FIV-Pet but were only partially protected against FIV-GL8. ${ }^{32}$ These antibodies may have contributed to protection from FIVPet, although this is not known for certain. However, it is unlikely that antiV3 antibodies alone were responsible, because in other experiments cats vaccinated with V3 peptides that include an immunodominant B-cell epitope were not protected against FIV-Pet. ${ }^{44}$ These findings suggest that other immune mechanisms are required for protection against most naturally occurring viruses.

Neutralization assays employing feline blood mononuclear cells or Tcell lines to measure residual infectivity, such as MBM or Mya-1, are generally considered to be more appropriate indicators of antibody activity because they may be relevant to immunity in vivo. However, serum virus neutralizing antibody titers in these systems have generally been low, making interpretation of results difficult. Some of the problems of measuring antibody in this way in cats vaccinated with inactivated virus or virusinfected cells were resolved by preabsorbing the sera with the cells in which the virus was prepared..$^{50}$ This procedure appears to remove anticell activity in the sera and thereby enhances virus neutralizing antibodies titers. Using this technique, virus neutralizing antibodies have been demonstrated in vaccinated cats, but again it is not clear whether this activity operates in vivo or contributes to protection.

\section{Clades}

An unresolved and very important issue about HIV vaccination is whether clades are relevant to vaccination. Do clades represent different 
antigenic types and if so, should vaccines be designed to include antigens of the prevalent clade(s) in a particular geographic area? FIV appears to be an excellent model in which to answer these questions. FIV exists in at least 5 clades or subtypes (A-E), and in some geographical areas these clades are distinct. Thus, in analyses of FIV isolates made in Italy and the $\mathrm{UK}$, it was found that all of the Italian isolates belonged to clade $\mathrm{B},{ }^{55}$ while all of the UK isolates were of clade A (Alexandra Müller and Mauro Pistello, personal communication). In Austria and southern Germany there appears to be a mixture of the two clades, including recombinants. ${ }^{69}$ This curious distribution may be due to the patterns of migration of cats and the evolution of FIV in these cat populations. Additional clades and recombinants have been identified throughout the world. ${ }^{62}$

Unfortunately it has not yet been possible to resolve the issue of whether FIV clades represent serotypes because of the difficulties in antigenic typing using virus neutralization, as described above. An indication that there may be clade-specific differences comes from a comparison of the neutralization of viruses representing five different clades, ${ }^{36}$ although insufficient isolates were examined to provide a comprehensive view of antigenic relationships. A potential further complication is the finding of type-specific neutralization within viruses of clade A using the CRFKbased assay. ${ }^{52}$ There have been few reports of antigenic relationships between primary FIV isolates, predictably because of the technical difficulties encountered. One study of 15 Italian isolates of clade B confirmed their resistance to neutralization and failed to reveal any correlation between behavior in neutralization assays and genetic relatedness or epidemiological distribution. ${ }^{13}$ Experience in the UK with clade A viruses has been similar (Alexandra Müller, personal communication). This resistance appears to be highly conserved in FIV, as infection of cats with neutralization-sensitive virus results in the evolution of a neutralizationresistant population with time. ${ }^{4}$ Clearly this is a very important field of study that urgently requires further effort to clarify.

A pragmatic approach to the issue, which is feasible in the cat but not in man or macaques, has been to determine whether a vaccine that contains antigen(s) derived from one clade can protect against challenge with a virus of another clade. So far this has not been done in a systematic way, although $\mathrm{Pu}$ et al. ${ }^{59}$ showed that cats vaccinated with an inactivated cell vaccine containing a mixture of clades $A$ and $D$ were protected more effectively against challenge with viruses of clades $\mathrm{A}, \mathrm{B}$, or $\mathrm{C}$ than cats vaccinated with a clade A virus alone. The commercial vaccine derived from that experimental vaccine protected completely against a further clade B virus. ${ }^{58}$ This information is of practical significance as FIV of clade B is widely distributed in the United States and parts of Europe. The generality of these results needs to be confirmed by the use of further challenge viruses rep- 
resenting all FIV clades. This cross-clade protection implies, however, that there are immunogens in common among clades.

\section{Virulence}

While the virulence of a virus used for the challenge of vaccinated cats has to be taken into account in assessing vaccine efficacy, as discussed below, it is not so clear if virulence is an important consideration in the choice of virus to be used in a vaccine. Do virulent viruses have other phenotypic characteristics that make them more attractive as immunogens?

Cell tropism is one characteristic that is almost certainly an important factor in virulence. Like HIV, FIV has a tropism for $\mathrm{CD} 4^{+} \mathrm{T}$ lymphocytes. As described previously, the primary receptor for FIV is CD134 ${ }^{66}$ and the coreceptor is CXCR $4{ }^{78}$ It is probable that the viruses transmitted in nature, accordingly most relevant to vaccine development, require both of these molecules for virus entry into cells. Viruses in a minority of primary isolates of FIV, as well as certain "laboratory-adapted" strains, are able to infect cells directly through an interaction between the V3 region of the SU protein and CXCR4 ${ }^{78,79}$ Although only a few of these viruses have been tested for their capacity to replicate in vivo, those that have been inoculated into cats establish lower virus loads, and consequently are considered to be less virulent, than more "primary" isolates. By contrast, it is considered that the CXCR4-tropic HIVs that appear during the terminal phases of infection are somehow associated with the decline in immune responsiveness of the host, and therefore are more virulent than the primary CCR5-tropic viruses that are initially present after infection. Experience with FIV suggests that in fact the viruses that enter cells using only the coreceptor may be a product of the immunodeficiency rather than the cause. It is relevant to this review that in the cat there appears to be pressure on these CXCR4-tropic FIVs to evolve into viruses with a phenotype more like that of the primary isolates, which use both receptors. ${ }^{33}$ Direct inoculation of a CXCR4 tropic FIV that established a very low virus load was followed, almost 3 years later, by the emergence of a virus population that appeared to have a change in receptor usage. When inoculated into kittens, these variant viruses established a higher virus load than the parental virus, similar to that following infection with a "primary" isolate. Consequently, there appeared to be selection pressure on the virus to evolve a phenotype that was more suited for long-term survival in its host.

The association between receptor usage, cell tropism, and virulence has yet to be fully determined. It is important that this association be unraveled because a great deal depends on the answer, particularly the choice of viruses that should be included in a vaccine for HIV or FIV and 
which should be used as challenge viruses in FIV vaccine trials to measure efficacy.

\section{Immune Responses to Vaccination and Correlates of Protection}

It is often asserted that to be effective a vaccine should induce an immune response that is equivalent to that which occurs in individuals who have been challenged with the cognate infectious agent and have subsequently recovered. The problem with defining the type of response to HIV or FIV that should be induced is that these viruses establish persistent infections from which the infected individual never recovers, even though they possess strong antiviral immune responses. Accordingly, it can also be argued that since the responses that are observed in the course of the infection do not eliminate the virus, they may not necessarily be indicators of the type of immunity that would be desirable in a protective vaccine.

The protection that is afforded by inactivated virus vaccines against FIV has been exploited to determine the immune correlates of vaccineinduced protection. An experiment with an inactivated virus vaccine that was manipulated to protect only a proportion of vaccinated cats allowed a comparison of the immune responses following vaccination, which resulted in either protection or the establishment of a persistent infection. ${ }^{21,28}$ While virus neutralizing antibodies appeared to be correlated with protection in the period immediately following virus challenge, CTL induced early after vaccination correlated with protection from further challenge 8 months later. These results suggested that perhaps a more universal response, in which both virus neutralizing antibodies and CTL were induced, is beneficial in vaccination. That each component is important in protection is suggested by the results of experiments in which protection could be transferred from successfully vaccinated cats by either serum ${ }^{25}$ or blood mononuclear cells. ${ }^{61}$ Whether the conclusions from these experiments with inactivated virus vaccines are valid also for other types of vaccines is not known. Since vaccines other than inactivated vaccines have not been entirely successful, it is not yet possible to determine directly the correlates of whatever protection they have provided.

\section{Challenge Systems}

Although the measurement of immune responses elicited by vaccination may give a valuable indication of the immunogenicity of a vaccine, it is still not entirely clear what immune responses may be protective. A broad range of cellular and humoral responses may be required or specific antibody responses to defined epitopes may be essential. Furthermore, the 
contribution to protection made by nonspecific innate immune responses (e.g., NK cells) is uncertain. In the absence of such correlates of protection, the assessment of vaccine efficacy is only possible using a challenge model. Further, the choice of an appropriate challenge is clearly important. There are four factors that should be considered: choice of virus strain, source of virus, challenge route, and dose of inoculum.

\section{Choice of Challenge Virus Strains}

There are a number of viral strains that have been used in efficacy studies, as illustrated in Tables I, II, and III. These strains vary significantly in their virulence, as assessed by viral loads attained and by reduction in $\mathrm{CD} 4^{+}$T-lymphocyte numbers following challenge. A further consideration is whether a homologous or heterologous challenge should be used. Choice of challenge strain may be influenced by geography; for example, in northern Europe clade A viruses predominate, while in central and southern Europe, clade B viruses are more common. Studies on field cases of FIV have shown that the majority of infected cats have relatively high viral loads and have depressed CD4 ${ }^{+}$T-lymphocyte counts. This supports the use of more pathogenic virus as a challenge strain for vaccine studies. In addition, this provides a realistic model for HIV, where high viral loads and suppression of CD4 counts are typically seen in infected patients. The feline model offers good opportunities to study the effect of viral variation on the ability of vaccines to protect against challenge by viruses of different clades and of different pathogenicity.

\section{Source and Type of Virus Inoculum}

It is believed that FIV is transmitted mainly by biting and, therefore, through the traumatic transfer of virus or virus-infected cells in the saliva. The dilemma in choosing the most appropriate source of virus is to balance simulation of natural infection with the practicalities of obtaining a suitable and reproducible inoculum. Infected saliva has not been used because of the difficulties in obtaining sufficient quantities of acceptable quality. The materials that have been most widely employed are free virus or infected cells grown in cultures of feline T-cells, either primary blood mononuclear cells or cell lines. The use of virus derived from molecular clones may be preferable, as it ensures consistency between experiments and avoids viral attenuation that can occur with long-term culture in vitro. Increasingly, virus-containing plasma from cats infected with an appropriate FIV strain is used. Although virus grown in vitro is more readily controlled, virus obtained ex vivo may represent more closely the state of the virus that is transmitted naturally; for example, in terms of its resistance or susceptibility to neutralizing antibodies. 


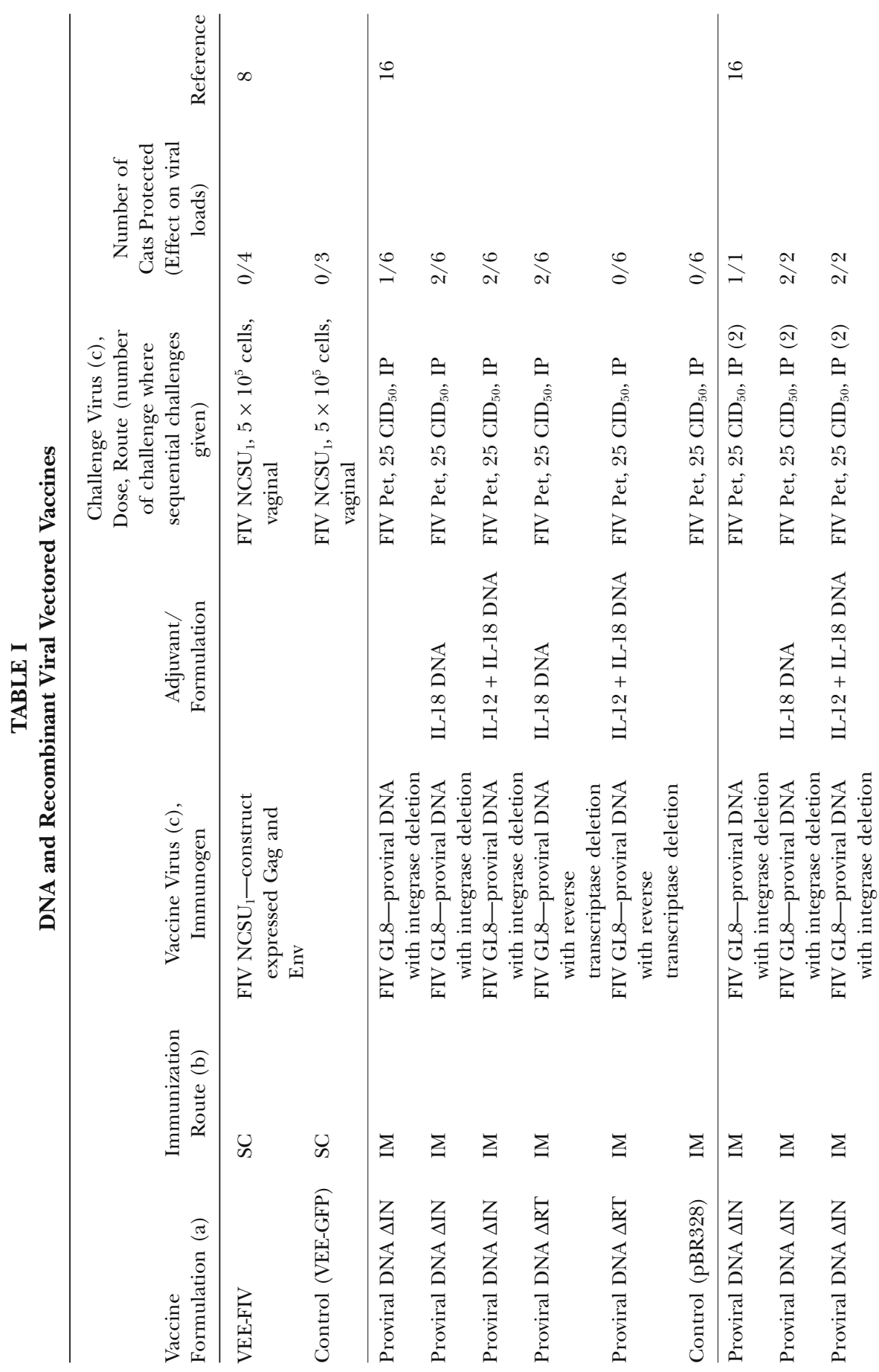




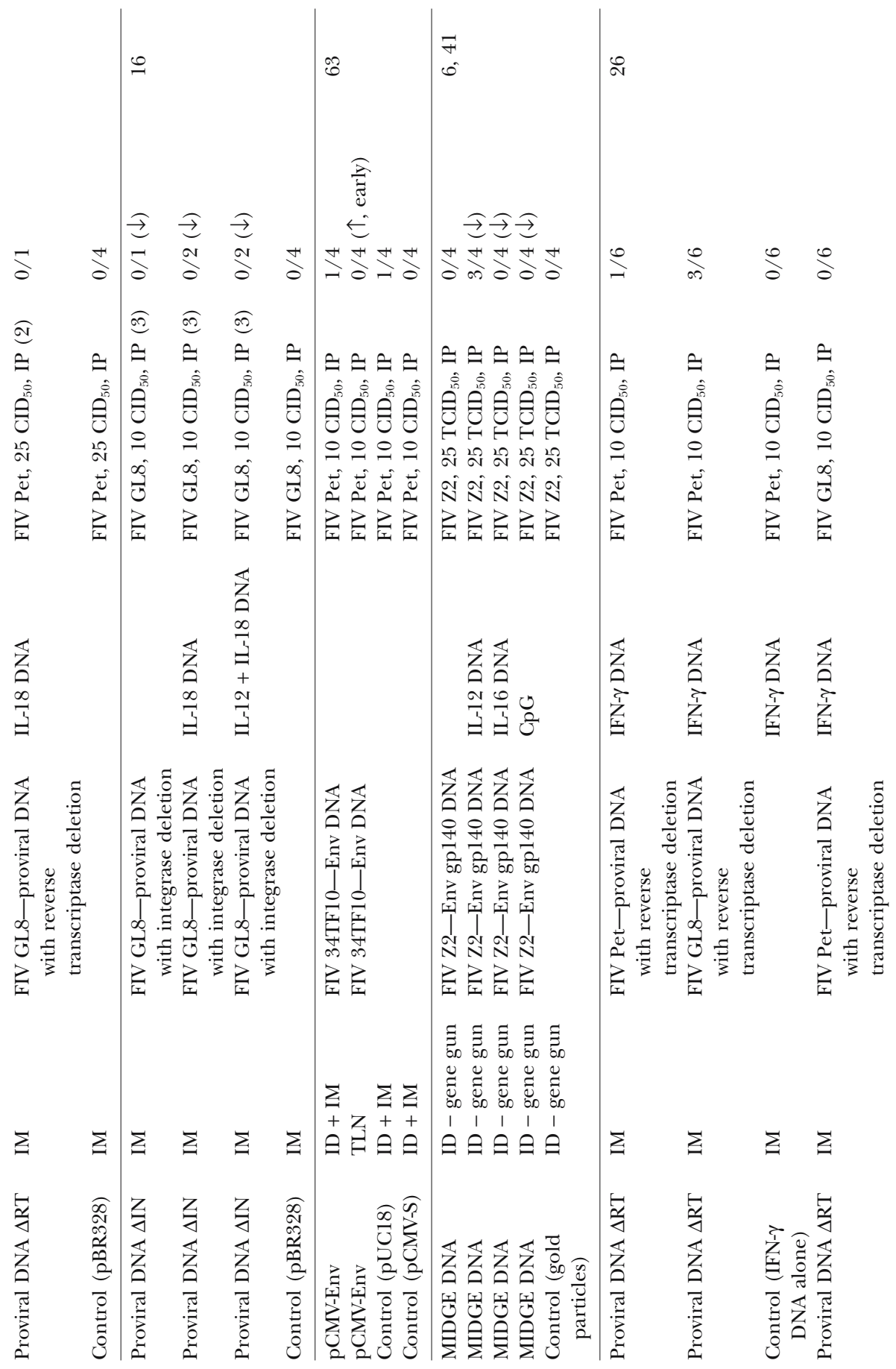




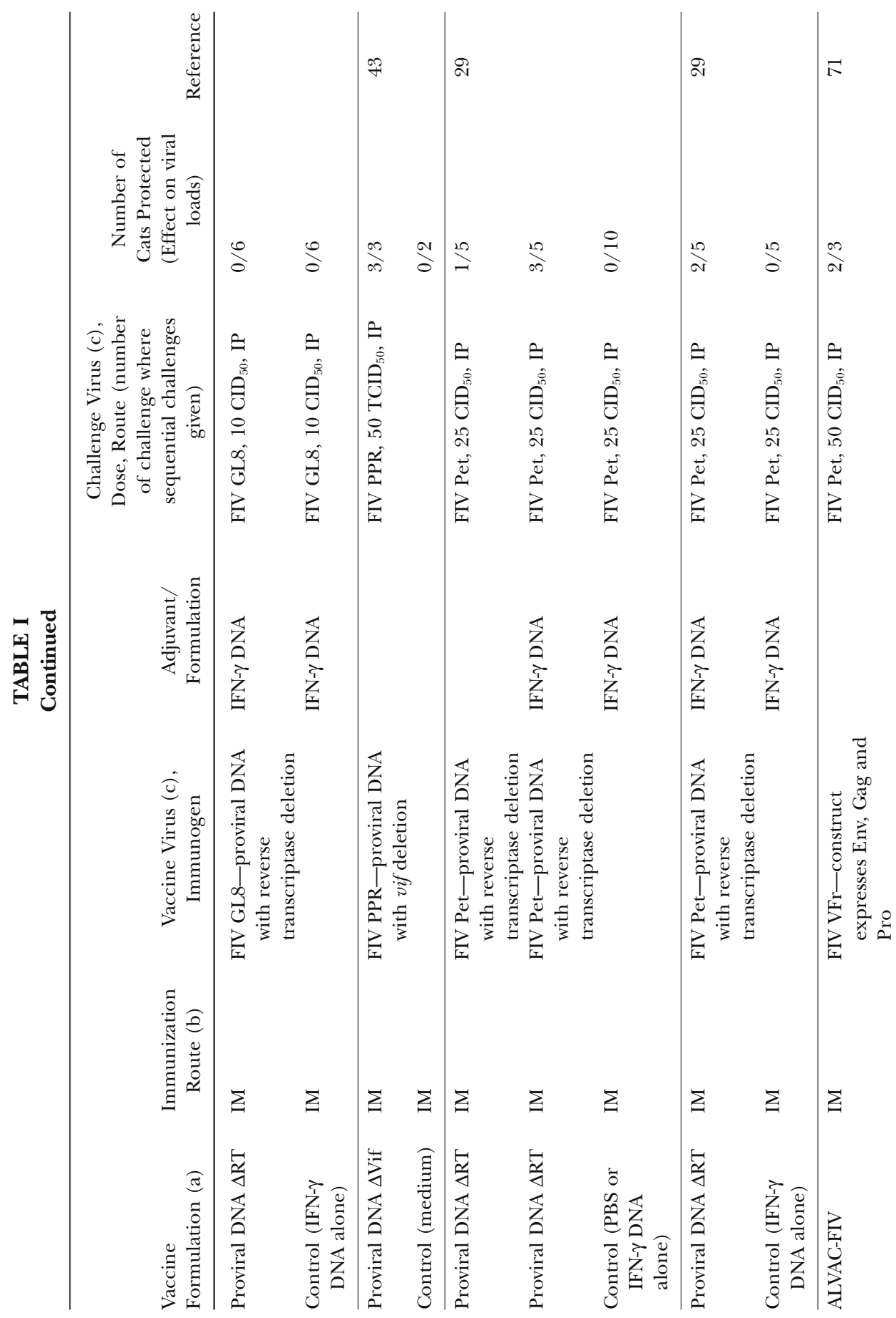




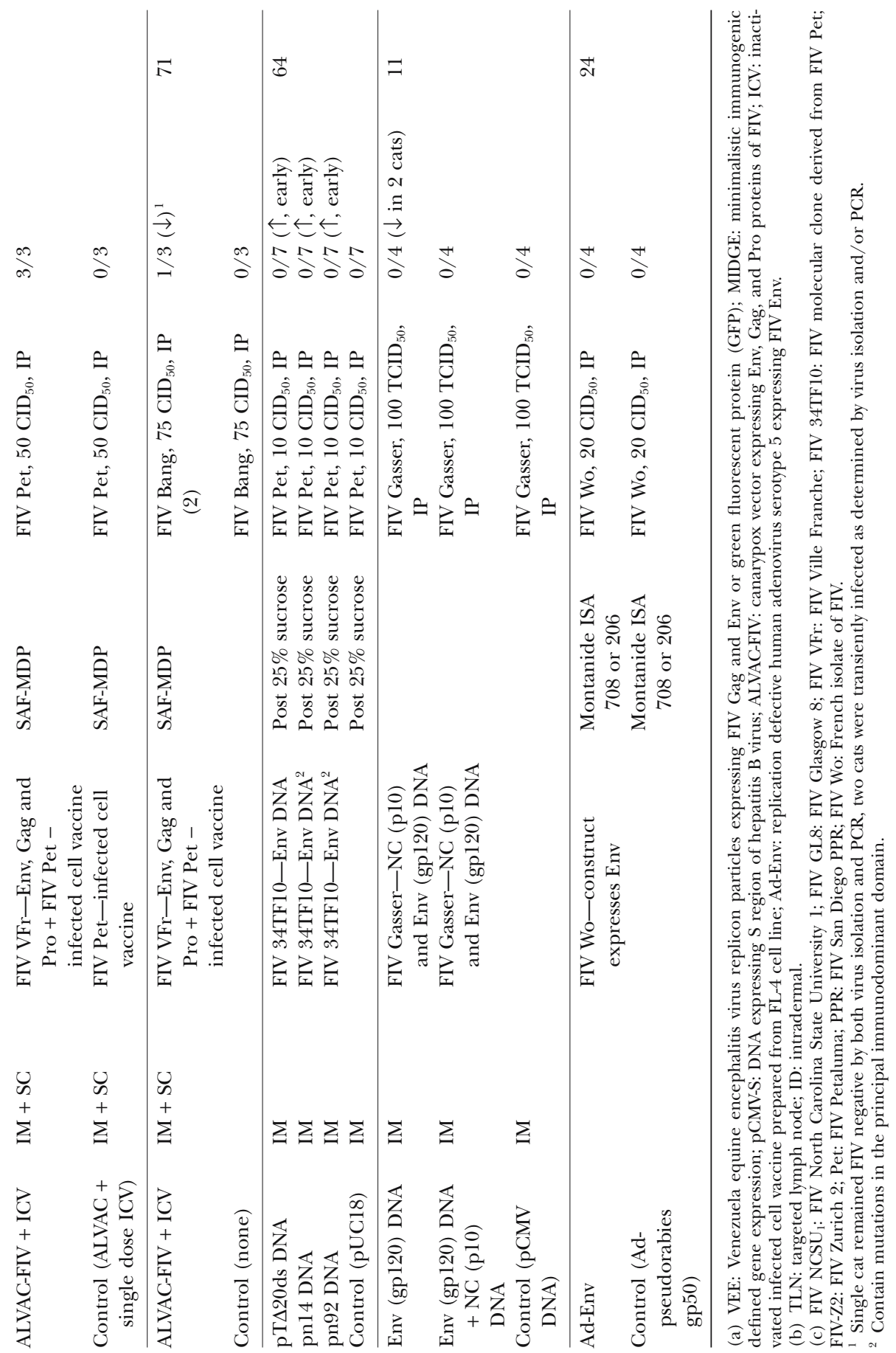




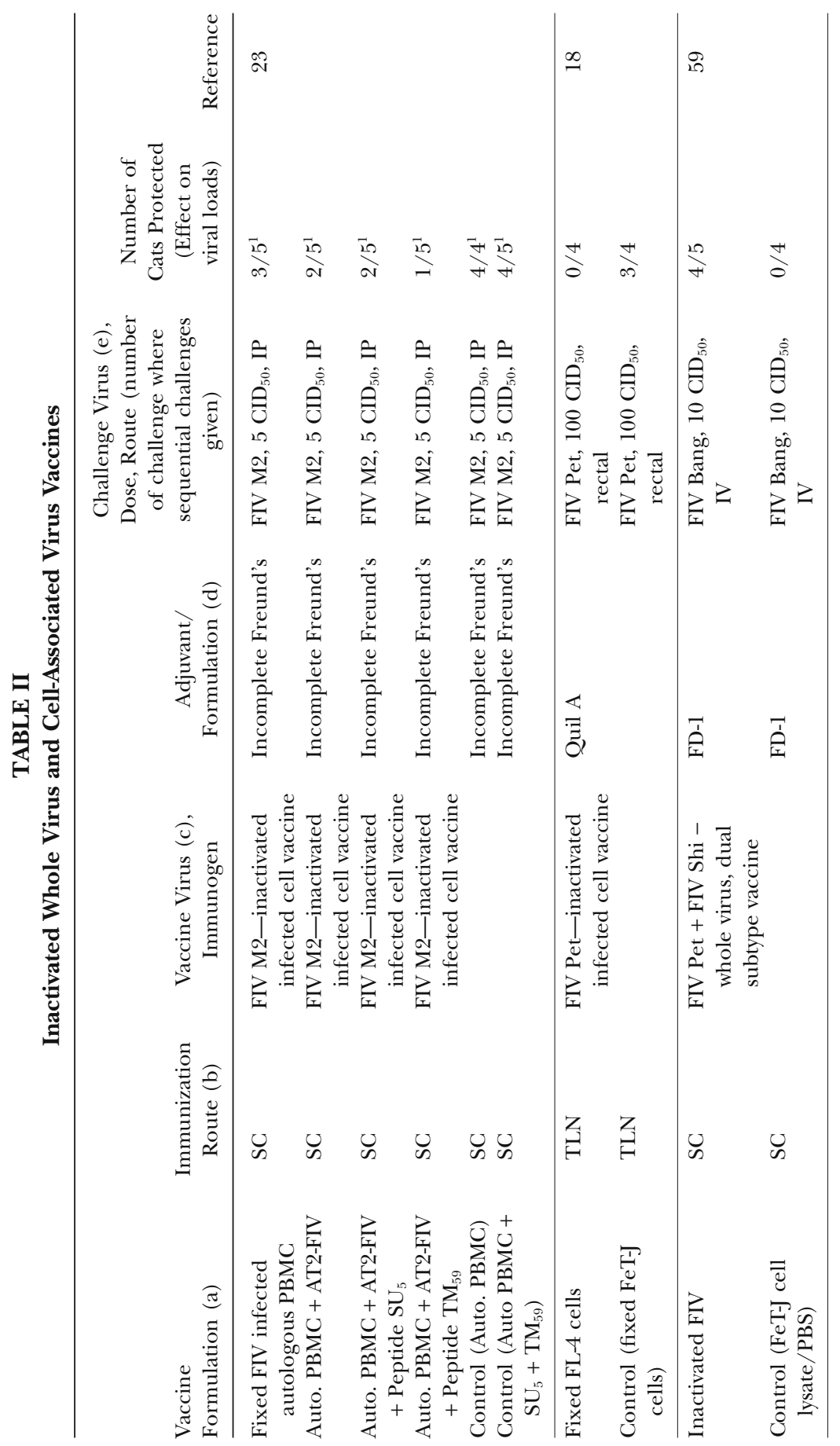




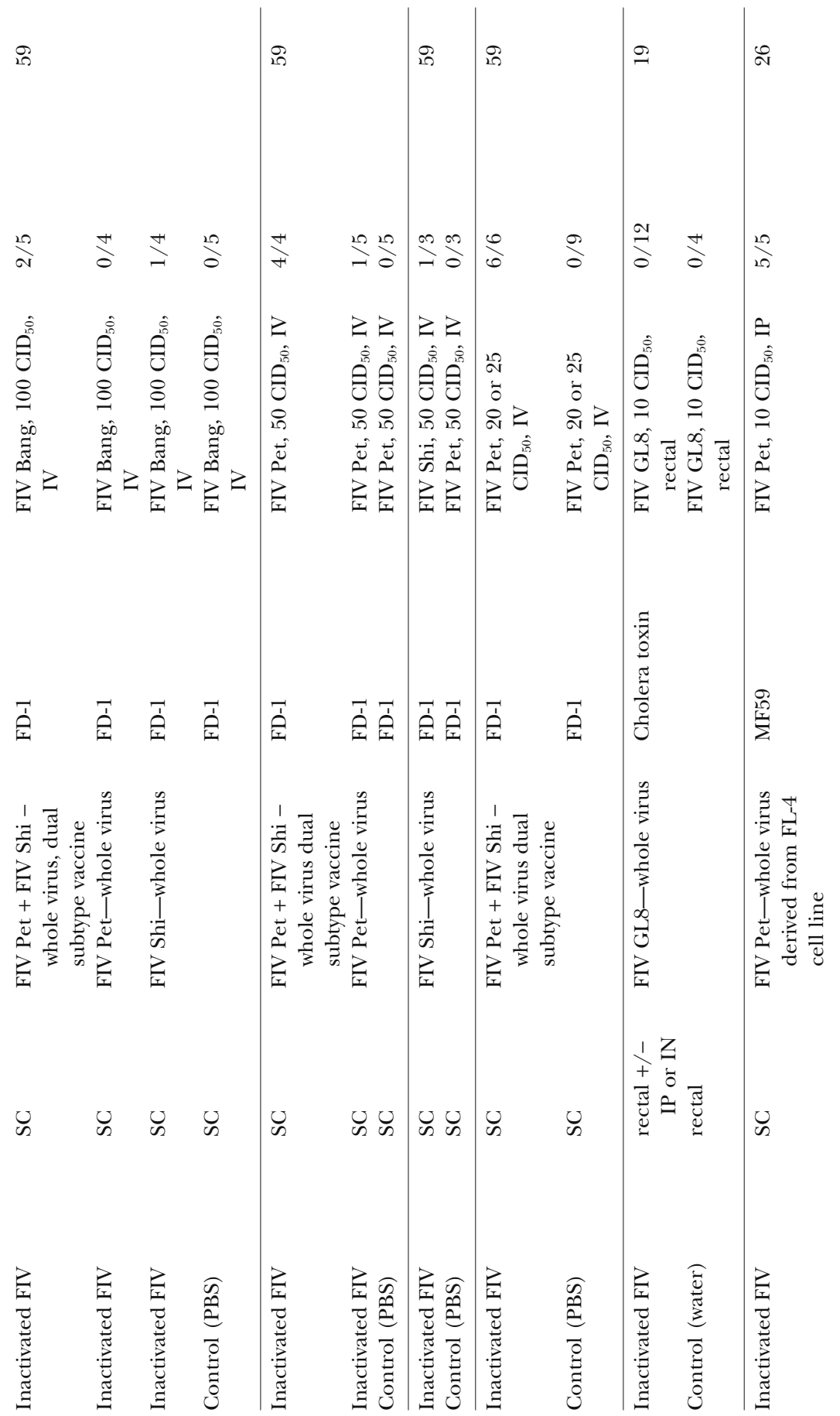




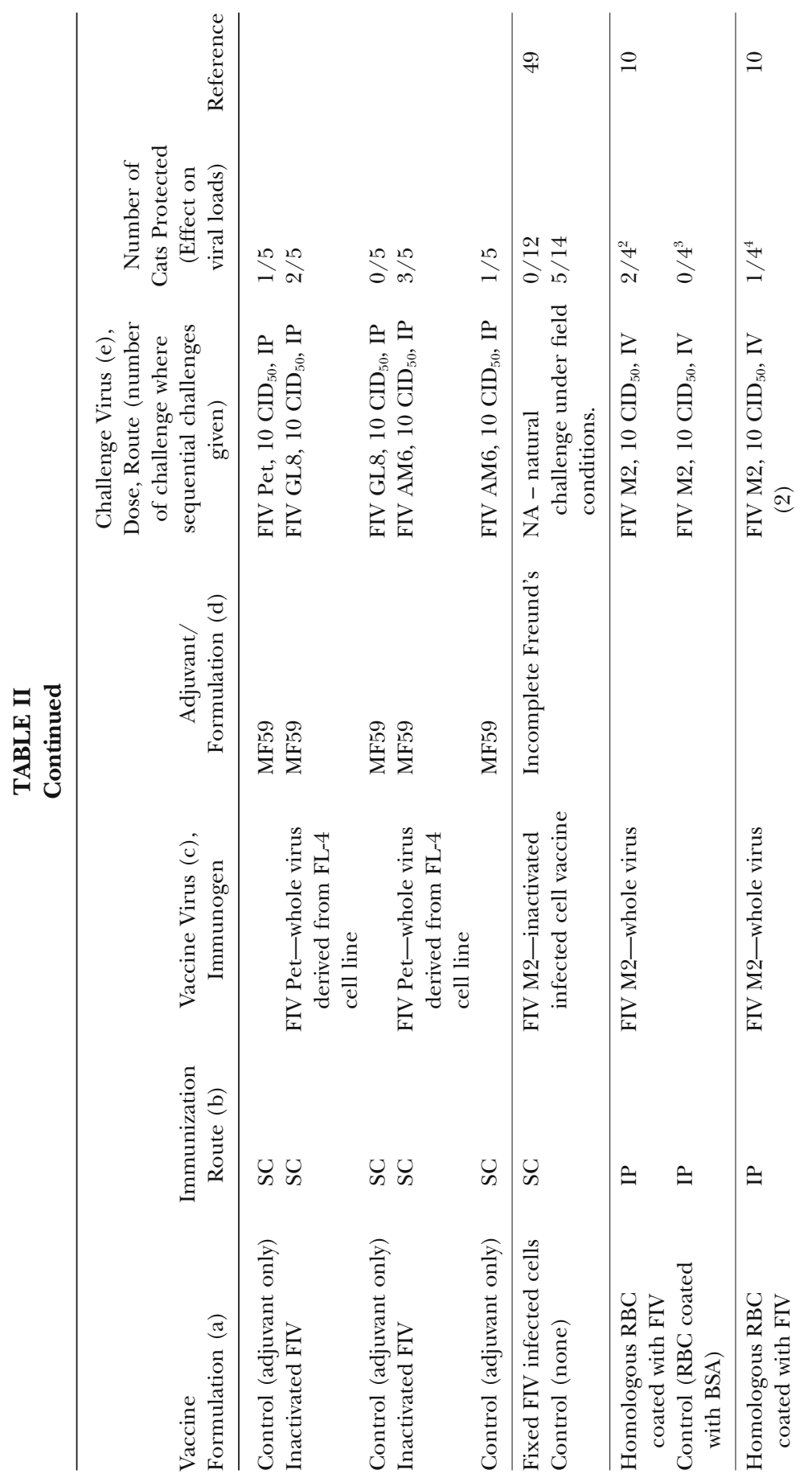




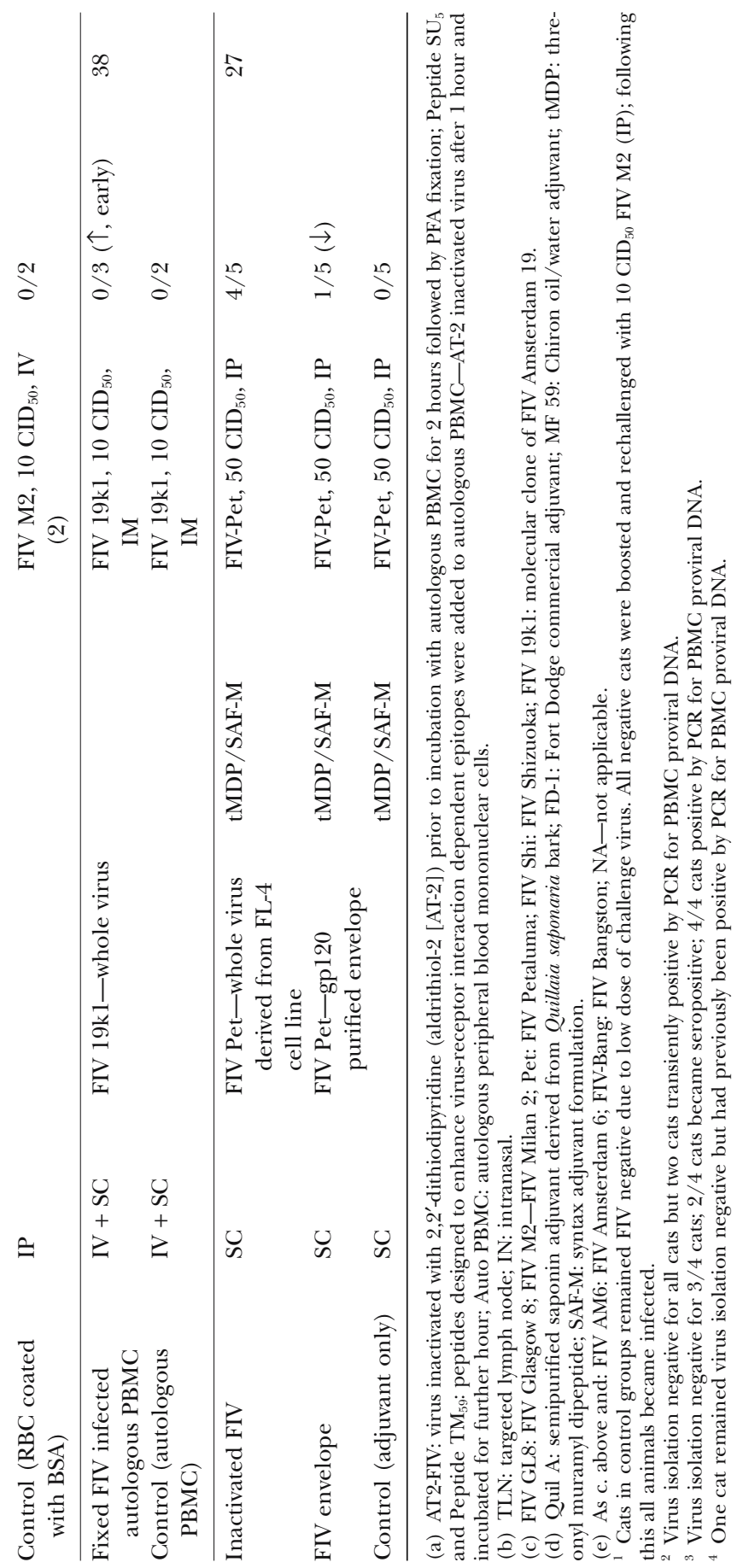




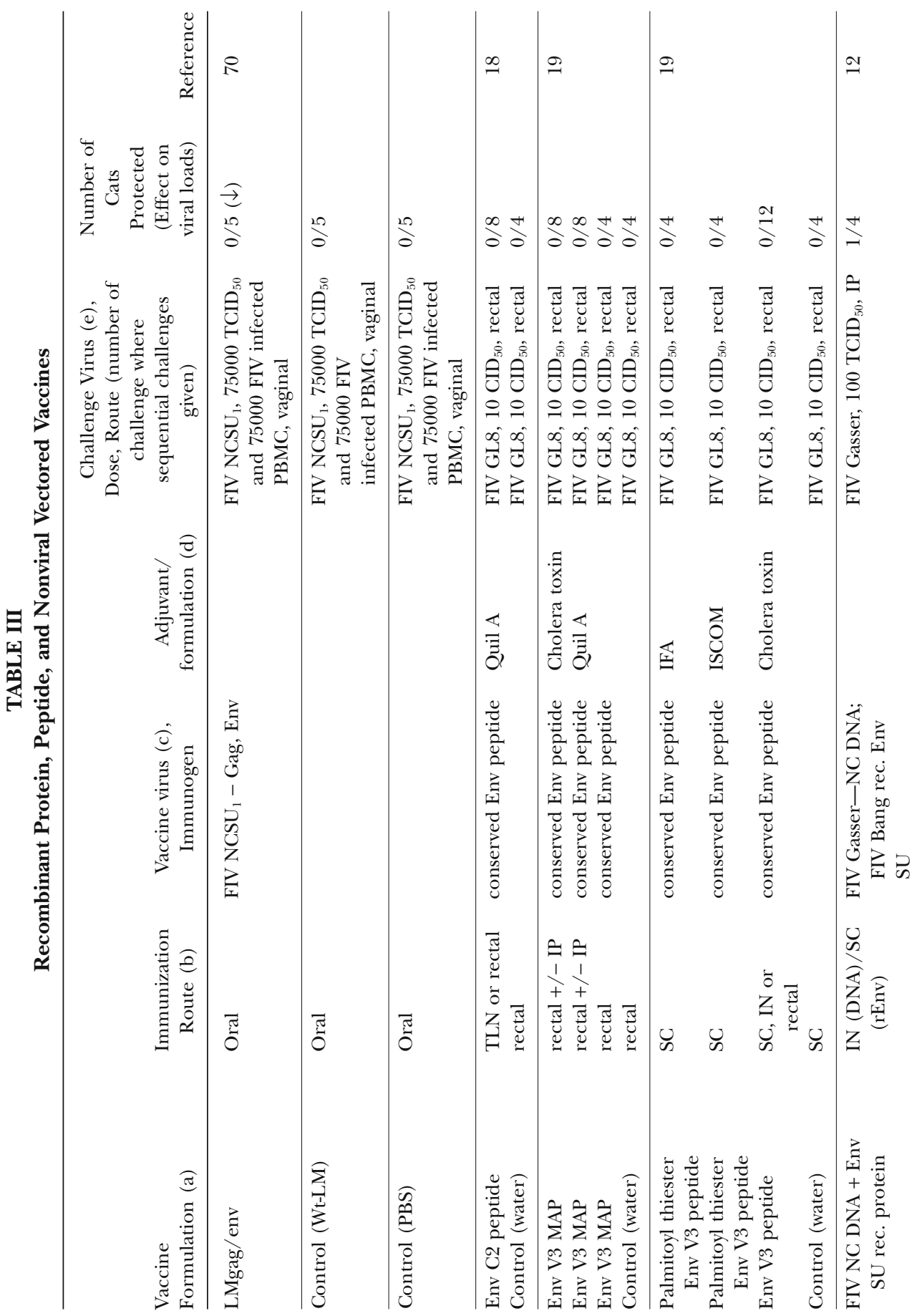




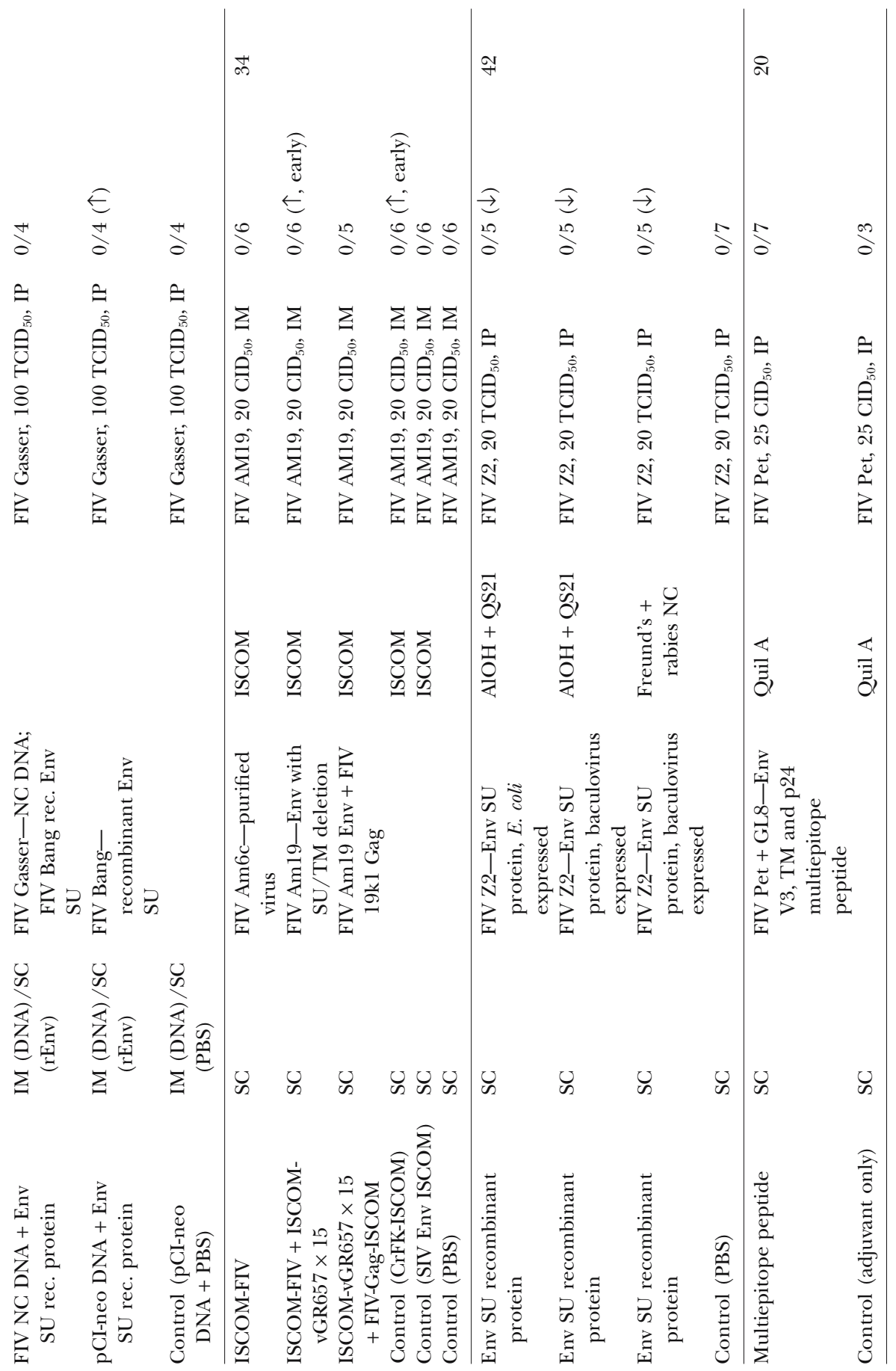




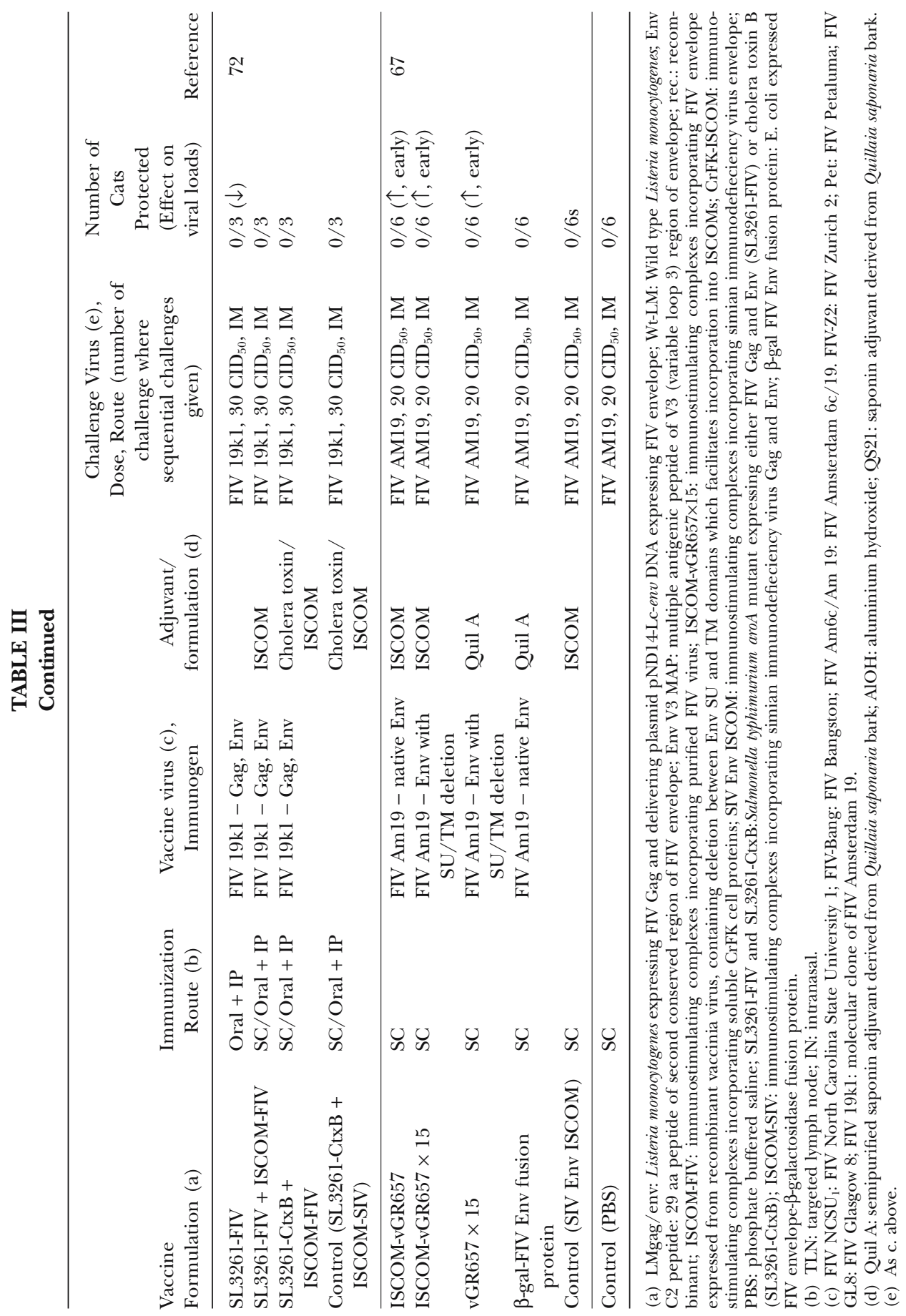




\section{Route of Challenge}

In assessing the efficacy of FIV vaccines in the development of products for use in the target species, the challenge should be delivered in a manner that is relevant to the route of infection by which natural transmission occurs. This being the case, establishing the outcome of housing vaccinated and nonvaccinated cats together with healthy persistently infected cats should provide the most natural and realistic measure of vaccine efficacy. However, for practical use, direct parenteral inoculation of virus has to be employed. In attempts to provide a model of sexual transmission of HIV, mucosal challenge by FIV has also been used.

Natural Challenge. A clear advantage of the FIV model over the SIV model is that ultimately the testing of a vaccine in its natural host under field conditions is possible. This provides the most realistic assessment of how well the vaccine performs in its intended environment. The prevalence of FIV is quite high in many populations of cats, with estimates ranging from $1-12 \%$ in the healthy pet cat population and up to $100 \%$ in small populations. This high prevalence might suggest that it would be easy to test FIV vaccines in a natural setting with relatively small numbers of cats, either under experimental conditions or in the field. Unfortunately, this is not the case. In situations of natural transmission among pet cats in the field it would be difficult, if not impossible, to obtain permission from regulatory authorities to carry out the experiment; keeping pet or shelter cats in a situation in which unvaccinated individuals might be infected is not appealing.

In the experimental situation, which simulates natural transmission, the problem is achieving a sufficiently high incidence of transmission of the infection, particularly among cats that are well socialized and nonaggressive toward each other. Group sizes need to be large, to ensure statistically meaningful results, because a portion of vaccinates is likely to remain uninfected following challenge. The experience of many is that cats housed with FIVinfected animals may remain uninfected over periods of years. However, in some cases regular, if slow, spread of infection has been recorded. ${ }^{1}$

These potential problems ensure that testing of the majority of candidate vaccines must still be performed in experimental animals, with challenge virus being administered artificially. How can we make these experiments more realistic? Should we consider using a dose of virus that represents a more natural challenge or use multiple lower doses of virus? The hope is that vaccines that are able to prevent infection in an experimental setting with a "robust" challenge may be more likely to provide significant protection in pet cats in the field.

Inoculation of Challenge Virus. As discussed above, there is a difference in the route of natural transmission of FIV and HIV: HIV is transmitted across mucosal surfaces, while FIV is spread mainly by biting. Consequently, 
FIV can serve as a model for HIV vaccination in two ways. In the first, more obvious model, which we have been describing until now, the principles established in eliciting protection from a natural challenge may be able to be applied to HIV. The second model involves manipulation of the FIV system by attempting to protect cats against virus administered by the vaginal or rectal routes, which are not the natural means of transmission of FIV but may be more relevant to HIV.

Cats may be infected vaginally, rectally, or orally, ${ }^{51}$ although these mucosal routes require higher doses of virus than intramuscular, intraperitoneal, or intravenous inoculation to produce persistent infection. Infection may be more readily established by rectal or vaginal routes with cell-associated virus than cell-free virus. ${ }^{5}$ This is in agreement with the infectious doses required to infect macaques with SIV by these routes. ${ }^{2,68}$ Vaginal inoculation is more efficient than rectal inoculation, while oronasal administration is the least effective method of infection. ${ }^{7}$

Clearly the route of viral challenge may influence the ability of vaccines to protect against infection or disease. While infection by the intramuscular and intraperitoneal routes requires relatively low amounts of virus for infection, mucosal infection by either the vaginal, rectal, or intranasal/oral routes requires large amounts: up to four logs higher than that required to establish infection by the intravenous or intraperitoneal routes. The implication of this difference is that HIV may similarly be more readily transmitted by intravenous drug use than by sexual transmission. What remains to be determined, although seems very likely, is whether vaccination may more readily prevent infection by mucosal compared to parenteral inoculation. The desired immune responses required to prevent infection are almost certainly different depending on the route of exposure to virus. Examples of the results of vaccination trials using mucosal challenge are discussed below.

Dose of Challenge Virus. The dose of viral inoculum used for challenge is typically chosen to be sufficiently high to ensure that all nonvaccinated controls become infected; usually 10-50 median cat infectious doses of virus are used. However, this dose is likely to be far greater than would be encountered in a natural challenge. It is possible, therefore, that vaccination trials carried out using these challenge doses may underestimate the potential efficacy of vaccines in a field setting. This contention is supported by the vaccine trial by Matteucci et al., ${ }^{49}$ which was performed in a population of feral cats in a private shelter where FIV was endemic, with a prevalence of 29 to $58 \%$. Animals were vaccinated with six doses of a FIV clade B paraformaldehyde-inactivated infected cell vaccine and observed for a 28-month period after the first immunisation. Although 5 of 14 control animals became infected, all 12 vaccinates remained free of infection. This result contrasts with the relatively modest success obtained in laboratory cats using similar vaccines. 


\section{Measurement of the Outcomes of Vaccination}

In assessing the success of vaccine experiments, four potential outcomes may be envisaged. The vaccine may provide robust protection, inducing sterilizing immunity, where it is not possible to isolate infectious virus or detect viral RNA or proviral DNA by the polymerase chain reaction (PCR) following challenge. Although they may not provide sterilizing immunity, vaccines may provide significant protection, leading to a decrease in viral loads in the blood or lymphoid tissues following challenge. Alternatively, vaccines may fail to provide any degree of protection, or worse, may actually enhance infection following challenge. Examples of each of these outcomes may be seen in Tables I-III. Many vaccines have failed to induce significant protection. This has been the outcome even when vaccination has induced significant anti-viral immune responses. By contrast, some degree of protection has been achieved with vaccines that failed to activate one or another arm of a specific immune response. These findings further emphasize the need for viral challenge when assessing vaccine efficacy.

With experience of lentiviral vaccine development, the realization that the quality of the immune response induced by vaccination might be insufficient to provide sterilizing immunity against infection has given rise to the hope that it might control subsequent infection sufficiently to reduce the transmissibility of the virus from the infected individual and to prevent the progressive decline to disease and death. Confirmation that the risk of transmission can be reduced by vaccination should be possible with FIV, as it is should be perfectly feasible to quantify virus or proviral DNA in saliva. ${ }^{46}$ Surprisingly, very little work appears to have been done on this important subject.

The most worrying result for a candidate vaccine is the finding that infection is enhanced following challenge. This outcome has been observed with a number of different types of FIV vaccine, including inactivated whole cell vaccines, some envelope subunit vaccines, and DNA vaccines encoding viral envelope. A number of potential mechanisms for such enhancement have been proposed and are discussed below.

\section{EXAMPLES OF FIV VACGINES}

\section{Inactivated Virus and Virus-Infected Cell Vaccines}

In spite of the number of variables associated with the challenge system, if a vaccine can be shown to be effective in cats against a virulent challenge with FIV, given the biological similarities between the two lentiviruses, it must be considered to be a serious candidate for development as an HIV vaccine. With this in mind, what lessons have we learned 
from the cat? The results of recent FIV vaccine trials shown in Tables I-III illustrate the number of candidate vaccines that are in development. While the earliest FIV vaccines to be studied were those based on virus or infected cells inactivated with paraformaldehyde, since then many approaches have been tried. These include peptide and recombinant proteins, DNA vaccines, and viral vectors. However, despite the application of new technologies to FIV vaccine development, and while DNA vaccines have shown early promise, inactivated virus and infected cell vaccines remain the most successful.

\section{Inactivated Virus Vaccines}

The whole inactivated virus vaccine pioneered by Yamamoto and her colleagues provided complete protection against challenge with homologous virus (FIV-Pet) ${ }^{82}$ and another strain of clade A. ${ }^{81}$ Hosie et al. ${ }^{32}$ confirmed these results and showed subsequently that this vaccine, although not providing full protection against challenge with a heterologous virus (FIV-GL8), significantly reduced the virus load. ${ }^{26}$ The reasons for the difference in the degree of protection achieved against challenge by the two viruses were not entirely clear but, as discussed above, a strong possibility is that the greater virulence of the FIV-GL8 strain was responsible. A virus that establishes a high virus load might be more difficult to protect against by vaccination, either because it grows more rapidly following infection or establishes infection in cells that are not accessible to the immune response induced by the vaccine. Another possible explanation is that the two viruses differ in antigenicity. In the CRFK-based neutralization assay, it was shown that although FIV-Pet and FIV-GL8, both of which are of clade A, were cross-neutralized by sera derived from cats infected with either virus, there was a degree of antigenic strain specificity. ${ }^{52}$ A third possibility, mentioned previously, is that the FIV-Pet virus was more readily neutralized than FIV-GL8 by the particular antibody induced by vaccination, such that the effective dose of virus was rapidly reduced immediately following challenge.

If the virulence of a virus indicates a phenotype that should be incorporated into a vaccine in order to provide effective protection, then viruses such as FIV-GL8 should be prime candidates. However, early attempts to produce an effective inactivated virus vaccine based on FIV-GL8 were unsuccessful. ${ }^{31}$ This lack of efficacy was ascribed to the poor preservation of SU on the vaccine virus, compared to the FIV-Pet from FL4 cells. In an attempt to produce a vaccine containing FIV-GL8 particles with high levels of SU, a molecular clone was modified to produce a virus in which the endocytosis signal in the cytoplasmic tail of Env was mutated, thereby promoting an accumulation of virus at the infected cell surface and incorporation of $\mathrm{SU}$ into viral particles. ${ }^{30}$ A vaccine derived from these particles 
inactivated with paraformaldehyde provided partial protection from virulent FIV-GL8 challenge. Although the formulation of the two FIV-GL8 vaccines was quite different, it may be that the significant improvement of efficacy of the second vaccine was due to better preservation of SU on the vaccine virus particles. However, the degree of protection achieved by the second vaccine against FIV-GL8 challenge was not markedly greater than that afforded by a previous vaccine based on FIV-Pet. ${ }^{26}$ This outcome suggests that factors other than the quality of SU are necessary for protection against challenge by viruses of high virulence.

\section{Inactivated Virus-Infected Cell Vaccines}

Vaccines based on inactivated FIV-infected cells have also provided good protection. This material is attractive as a commercial proposition because it does not require expensive concentration or purification, and it contains the full range of viral proteins. In their initial experiments, Yamamoto et al. ${ }^{82}$ obtained essentially equivalent protection with vaccines containing either paraformaldehyde-inactivated whole virus or inactivated infected cell vaccines. In these experiments the vaccines were derived from the interleukin-2-independent FL4 cell line that is chronically infected with FIV-Pet, and the challenge was the homologous virus administered by the intraperitoneal route. In further developments of this approach, the vaccine was found to protect also against another virus of the same clade. ${ }^{81}$ The inclusion of cells infected with a second strain of FIV, FIV-Shi, belonging to clade $\mathrm{D}$, extended the efficacy of the vaccine, which now protected against challenge by three different FIV strains: FIV-Pet (clade A), FIV-Ban (clade B), and FIV-Shi (clade D). The commercial derivative of this vaccine was shown subsequently to protect against FIV-FC1, a "primary" isolate of clade B, a common clade in the United States. ${ }^{60}$ This virus was considered to be of high virulence as it caused a reduction in $\mathrm{CD} 4^{+} \mathrm{T}$-cell numbers in unvaccinated cats.

In an attempt to set a benchmark against which other vaccines could be judged, we tested the ability of this commercial vaccine to protect against challenge with the virulent UK isolate, FIV-GL8. The vaccine failed to provide sterile protection in any cats regardless of whether they were challenged by the intramuscular, intraperitoneal, or oronasal route. This raises the question of whether FIV-GL8 represents an excessive challenge. Studies of UK field isolates have shown that they typically produce high viral loads and depress CD4 ${ }^{+}$T-cell numbers, such that FIV-GL8 appears to be representative. However, it is not clear if there are other factors that may compromise the ability of vaccines to protect against this isolate. Ideally, vaccines would be tested against a panel of well-characterized field isolates, but unfortunately this is impractical at present. 
Confirmation of the efficacy of vaccines containing FIV-infected cells was provided by Matteucci et al. ${ }^{47} \mathrm{~A}$ vaccine based on paraformaldehydeinactivated cells of the MBM feline lymphoblast line infected with FIV-M2 protected cats when challenged with ex vivo, cell-free virus 4 months after vaccination. No significant protection was recorded when the cats were challenged 12 or 28 months after vaccination, indicating that the duration of immunity was short. Nevertheless, this vaccine protected cats in a natural setting over a period of 24 months, as described above. ${ }^{49}$

In contrast to these successes, other types of inactivated cell vaccines have not proven to be as protective. The substrate in which the vaccine virus is grown may have an effect on efficacy. Thus, a vaccine based on paraformaldehyde-inactivated CRFK cells or feline thymocytes infected with FIV-UT113 failed to protect cats on challenge with homologous virus. ${ }^{75}$ An even more alarming outcome was found in later trials of vaccines containing inactivated FIV-infected autologous T-cells. ${ }^{38}$ The rationale for these experiments was that FIV antigens would be presented in a MHC-matched manner. However, the challenge with homologous virus was found to enhance the challenge, indicated by a shorter period between challenge and the appearance of viraemia in the vaccinated cats versus the controls. Similar results were obtained by Giannecchini et al. ${ }^{23}$ in testing four vaccines based on inactivated infected autologous lymphoblasts.

\section{Inactivated HIV Vaccines}

There has been comparatively little interest in developing inactivated virus vaccines for HIV, despite the efficacy of some FIV vaccines and the extremely successful use of many killed vaccines for other human diseases. The main reason for the lack of interest is the danger arising from incomplete inactivation of infectious virus and the high cost of production for a virus that is required for large-scale use in poor countries.

Recently, inactivated HIV has been used as the boost in a prime-boost vaccination regime in an attempt to protect macaques from infection with a SIV-HIV recombinant virus (SHIV) ${ }^{80}$ The rationale for using inactivated virus particles was that they might induce high levels of virus neutralizing antibodies to complement the cell-mediated immunity likely to be elicited by the priming component, a vaccinia virus recombinant expressing HIV and SIV structural proteins. The vaccine failed to prevent infection with the challenge, although virus loads were very much reduced compared to those in unvaccinated control animals, and the vaccinated macaques remained healthy over a period of 21 months while the controls developed AIDS within this period. 


\section{Attenuated Virus and DNA Vaccines}

Attenuated virus vaccines offer several advantages over inactivated vaccines. They can be relatively inexpensive to produce, often do not require an adjuvant for efficacy, and produce a robust immune response. Of relevance to the development of lentivirus vaccines is the capacity of attenuated vaccines to induce both antibody and cell-mediated immune responses. Viruses have traditionally been attenuated by prolonged passage in cell culture. However, the introduction of defined changes using molecular techniques offers a more refined and perhaps safer approach. The deletion of accessory lentiviral genes provides a method to reduce virulence without completely disabling virus replication and dissemination in vivo and has been extensively pursued in the SIV model. Attempts to produce a nef deleted SIV vaccine were based on the discovery that a number of individuals infected with an HIV variant deleted in nef showed slow disease progression. Although this approach showed initial promise, the eventual development of disease, both in vaccinated macaques and HIV-infected individuals, led to an obvious reluctance to pursue such vaccines for HIV. ${ }^{76}$

A further opportunity provided by the FIV model is the availability of viruses of low virulence that can be tested for their ability to protect against subsequent challenge with a more virulent virus. The possibility that FIVPet, attenuated by prolonged growth in vitro, could protect against a subsequent virulent challenge has been studied. Modest protection was seen against FIV-M2 administered intravenously. ${ }^{57}$ Excellent protection was achieved against intraperitoneal challenge with cell-free FIV-GL8 but not cell-associated vaginal challenge ${ }^{56}$ Although such vaccines are unlikely to be considered safe enough for clinical development, they may be able to provide a useful insight into both viral determinants of pathogenesis and immune correlates of protection.

A difficulty encountered with the use of attenuated virus vaccines is that of growing viral stocks to sufficient titers in vitro to produce the quantities required for vaccination. DNA vaccines offer an alternative method for exploring the immunogenicity of proviruses that can be rendered defective by selective deletions. The first successful example of this approach used a deletion in the reverse transcriptase gene to produce a DNA vaccine $(\Delta \mathrm{RT})$ that provided significant protection against challenge with the homologous virus, FIV-Pet. ${ }^{29}$ This encouraged the hope that vaccine protection might extend to more virulent isolates. However, subsequent studies have failed to demonstrate such significant levels of protection against FIV-GL8, using proviral DNA vaccines with either the $\Delta$ RT vaccine or a similar vaccine with a deletion in integrase. ${ }^{16,26}$ Attempts to improve levels of protection by using a variety of cytokine adjuvants and a prime-boost approach have also been unsuccessful. One of the most 
promising results shown by DNA vaccination, against FIV-PPR, used a proviral DNA vaccine attenuated by a deletion in vif. ${ }^{43}$ Unfortunately, the safety of such a vaccine is uncertain, with the possibility that the attenuated virus may revert to a virulent phenotype.

If DNA vaccines were to be developed for widespread use, then one concern that would need to be addressed is the use of vectors that do not contain antibiotic resistance genes. A system to accomplish this has been tested in the FIV model. Minimalistic, immunogenic defined gene expression (MIDGE) constructs encoding FIV Env and feline IL-12 and lacking unnecessary vector sequences have shown significant protection against challenge with FIV-Z2.6,41

The experience with DNA vaccines for FIV mirrors that of DNA vaccines for SIV and other viral pathogens. Although they have shown early promise, they have yet to produce levels of protection, when used alone, that suggest they may be applied to HIV. This has led to several approaches to try to improve their efficacy, including the use of cytokine adjuvants, inoculation of DNA vaccines in combination with viral vectors or proteins in a prime-boost approach, use of improved delivery systems, and alteration of codon usage to improve expression levels. Some of these approaches are currently also being tried for FIV. Should improved efficacy be attained then this would be of great value to the development of other lentiviral vaccines.

\section{Protein and Peptide Vaccines}

Early efforts to develop both HIV and FIV vaccines attempted to induce protective neutralizing antibodies. Although the majority of successful experiments in the FIV model have used whole inactivated or infected cell preparations, as outlined above, experiments have also been performed using subunit and peptide vaccines (Table III). These have largely been unsuccessful and indeed this result reflects the great challenge that is faced in developing antigens that will induce potent, broadly reactive antibodies that can mediate protection from HIV. It is likely that to be successful such vaccines will have to comprise protective epitopes that are very similar to those in the virus. Since the majority of these are conformationally dependent, it is expected that peptide immunogens are less likely to achieve this. The use of envelope gp120 as a vaccine has met with poor success, most likely due to the lack of authentic conformation of the monomer. This outcome has been seen in the FIV system where the relatively poor efficacy of a purified gp120 vaccine was in contrast to the robust protection provided by the whole inactivated virus from which the purified preparation was derived. ${ }^{27}$ The lack of efficacy of gp120 in animal models, however, does not appear to be a lesson that was heeded in the clinical development of an HIV vaccine, where gp120 was pursued at great cost as a prototypic HIV vaccine, as discussed above. 


\section{Viral Vectored Vaccines}

Like DNA vaccines, vaccination with viral vectors is effective at generating cell-mediated immune responses. Although relatively few studies have been performed with viral vectors for vaccination against FIV, one of the most effective vaccines for the other pathogenic feline retrovirus, FeLV, is a canarypox vector, which expresses FeLV Env and Gag proteins. Cats immunized with a "prime" of canarypox virus encoding FIV env and gagpolfollowed by a "boost" of inactivated FIV-infected cell vaccine were solidly protected against homologous challenge with clade A FIV-Pet. When subsequently challenged with clade B FIV-Bang, cats showed full to partial protection. ${ }^{71}$ The idea of combining a vaccine that can generate potent cell-mediated immunity with one that can generate potent antibody responses is one which has being adopted in an effort to develop an effective human AIDS vaccine. ${ }^{45}$ However, early data from a phase I and II clinical trial in humans of the prime-boost combination of canarypox and gp120 or gp160 are not encouraging. In this trial, individuals who became infected subsequent to vaccination showed no delay in the progression of infection compared to those receiving placebo. ${ }^{39}$

\section{Enhancement of Challenge by Vaccination}

The disturbing phenomenon of enhancement of the FIV challenge following vaccination, evidenced by an acceleration of the appearance of viraemia, a higher virus load, or an increase in the proportion of cats becoming infected compared to control cats, has been observed with several different types of vaccines. This effect has not been recognized in macaques vaccinated with $\mathrm{SIV}^{*}$ Therefore, it is not known whether enhancement is a danger to be avoided in HIV vaccination, although it is a concern, as sera from infected individuals may amplify HIV infection in vitro and the enhancing activity in serum has been suggested as a component in the progression to AIDS.

Two plausible mechanisms have been advanced to account for enhancement of FIV infection by vaccination. The first implicates antibodymediated infection of target cells, for example, by Fc or complement receptors. In experiments to evaluate several Env products as immunogens, enhancement produced in cats vaccinated with Env expressed by a vaccinia

* Since going to press enhancement has been recognized in the SIV model Ref: Staprans, S. I., Barry, A. P., Silvestri, G., Safrit, J. T., Kozyr, N., Sumpter, B., Nguyen, H., McClure, H., Montefiori, D., Cohen, J. I., Feinberg, M. B. (2004). Enhanced SIV replication and accelerated progression to AIDS in macaques primed to mount a CD4 T cell response to the SIV envelope protein. Proc. Natl. Acad. Sci. U.S.A 101, 13026-13031. 
recombinant was transferable to naïve cats by plasma from the vaccinated animals. ${ }^{67}$ Definition of the regions of Env that might be responsible for this effect proved to be elusive. ${ }^{35}$ Pancino and Sonigo ${ }^{53}$ showed that the highly conserved structure of the principal immunogenic determinant of TM, maintained through two delineating cysteines, was essential for viral infectivity and suggested that the induction of antibodies to this region, which represent a large proportion of serum anti-FIV antibodies in infected cats, might be a mechanism that has evolved to enhance viral entry and growth.

However, that the induction of antibodies specific for Env is not the only possible mechanism involved is evident from experiments in which enhancement was produced in cats immunized with vaccines that did not include Env and consequently could not elicit anti-Env antibodies; for example, a recombinant p24 (Gag) vaccine adjuvanted with immune stimulating complexes. ${ }^{31}$ In addition, enhancement might be due to the generation of effectors other than antibodies. Thus, Richardson et al. ${ }^{63}$ showed that a likely mechanism for increased viral growth in cats after challenge was an expansion of activated $T$ lymphocytes, induced by vaccination with a DNA Env vaccine that did not induce anti-FIV antibodies. In a previous trial of a similar vaccine, which had resulted in enhancement, the vaccinated cats had been challenged shortly after vaccination at a time when lymphocyte activation might have been at a peak. In the second trial, in an attempt to minimize this effect, the vaccinated cats were not challenged until 10 weeks after the final vaccination. The cats immunized by the intradermal/intramuscular route did not exhibit enhanced infection after challenge. However, the appearance of virus in the blood of some cats, in which vaccine was targeted to mesenteric lymph nodes, was very much accelerated. These cats had FIV-specific helper T-cell proliferative responses and their cells were more susceptible than normal cells to infection with FIV ex vivo. Although the number of subjects in these experiments was small, the results suggest that activated FIV-specific T-cells might be more susceptible to infection than nonspecific cells, as has been demonstrated for HIV. ${ }^{14}$ It is also possible that vaccination results in a change in the population of cells that are susceptible to infection. For example, the quantity and distribution of cells expressing receptors for FIV may be increased.

Of great concern for the welfare of cats is the finding that enhancement has been seen in trials of vaccines based on inactivated infected FL4 cells, which resulted in the production of the commercial FIV vaccine, ${ }^{15}$ and with other inactivated cell vaccines. ${ }^{23,38}$ In cats challenged 4 weeks after receiving their third dose of commercial vaccine, plasma viral loads were elevated at 2 weeks postchallenge compared to unvaccinated controls. Viral loads fell below those of controls by 8 weeks postchallenge, but the early rise suggests that wider viral dissemination and establishment of viral reservoirs may have occurred. ${ }^{15}$ 
Clearly, the potential for enhancement is of great importance, not just for the use of the FIV vaccine, but also for the development of HIV vaccines. It has been suggested that increasing the length of time following vaccination prior to challenge may reduce the risk of enhancement. However, prevention of exposure to the virus while the immune response "matures" and the possibly increased susceptibility to infection declines seems an unlikely proposition for a commercial vaccine.

\section{Vaccination Against Mucosal Challenge}

The development of mucosal vaccines against HIV is undoubtedly a rapidly growing area, given increased impetus with the finding that the gastrointestinal mucosa represents a major viral reservoir. ${ }^{74}$ As discussed above, much effort has been applied to developing the FIV model to accommodate challenge by a mucosal route that is relevant to HIV. Some degree of protection from vaginal challenge has been achieved by vaccination. Although parenteral vaccination with an inactivated virus vaccine did not protect against challenge with homologous virus, the vaccinated cats had significantly lower virus loads than control cats. ${ }^{48}$ In another approach, a recombinant vaccine consisting of an alphavirus replicon that delivered FIV gag and env given subcutaneously induced serum and mucosal anti-FIV antibodies but did not protect from vaginal challenge with FIV-NCSU-1, a virulent strain. ${ }^{8}$

The use of bacteria as vectors for mucosal vaccine delivery is also an area of growing interest for lentivirus vaccination. Early attempts to develop Salmonella as a vector for FIV vaccines met with only modest success. ${ }^{72,73}$ In contrast, in a more recent trial of a recombinant Listeria monocytogenes vector expressing FIV Gag and Env, a single oral dose of vaccine provided significant protection. ${ }^{70}$ Both vaccinated and control cats became infected following challenge with the virulent NCSU-1 strain of FIV, but the vaccinated cats had extremely low virus loads compared to the controls and did not suffer from the depletion of lymphocytes in the intestine or mesenteric lymph nodes as was found in the control cats.

Vaccine trials using rectal challenge have also been carried out. Mucosal immunization, with either a SU V3 peptide or inactivated infected cells, adjuvanted with quil A and cholera B toxin, although inducing FIV-specific antibody and T-cell proliferation, did not protect cats from rectal challenge with the homologous virus, FIV-GL8. ${ }^{19}$ More successful results were obtained with an inactivated FL4 cell vaccine when immunization was targeted to the iliac lymph nodes and rectal challenge was with homologous cell-free FIV-Pet. ${ }^{18}$ It is not known whether this difference in outcome in the second trial was due to a better preserved immunogen, more effective immunization, or because of the lower virulence of the FIV-Pet challenge. Challenge with cell-associated virus proved to be un- 
expectedly inefficient, even in control cats vaccinated with inactivated uninfected cells, which suggested that an anticell immune response had been induced that might have protected from challenge in a non-FIVspecific fashion.

As for parenteral challenge systems, the success or failure of vaccination against mucosal challenge could be due to a variety of factors, including choice of antigen delivery system and strain of challenge virus.

\section{CONCLUSIONS}

In this short review we have discussed some of the ways in which the development of FIV vaccines has been approached. The driving force behind many of these attempts has been to produce a vaccine that could be used in the field to prevent the spread of FIV among domestic cats. In addition it is recognized that if this end were to be achieved, the methodology might very well be applicable to the development of a vaccine against HIV in humans. So far, success has been tantalizingly close: a commercial vaccine has become available and an experimental vaccine has been shown to protect against challenge in a natural setting. Other vaccines have provided partial protection. Paradoxically, a valuable outcome of some of the trials of FIV vaccines that have failed to provide complete protection is that several confounding factors have been identified, which, by their resolution, may provide the basis for more effective vaccines in the future. For example, the commercial vaccine has been found to protect against some virus strains but not others. This result may be due to differences in virulence between the viruses used for challenge. Sufficient well-characterized FIV strains are now available to test if this is the reason. Another possibility is that there are antigenic differences between the viruses. Again, the availability of a very large number of primary FIV isolates of different clades from around the world means that the antigenic relationships between individual viruses and clades might be defined, and the practical significance of any difference might be tested directly by experimental challenge. The question of whether partial protection reduces the transmissibility of FIV can be determined by the quantification of virus in the saliva of vaccinated and challenged cats. Enhancement of infection following vaccination is a concern for the application of HIV vaccines in the field. Further definition of the factors responsible for enhancement and those that are necessary to overcome enhancement by certain FIV vaccines should be made.

Despite the opportunities provided by FIV to resolve these issues, which undoubtedly also apply to HIV vaccine development, the feline model has been relatively neglected by the AIDS research community. The crucial problems that have arisen in the course of FIV vaccine development will only be resolved by careful, systematic analysis of the viral and host factors 
responsible. We have no doubt that given more generous resources, many of these problems could be overcome, and the central tenets for the production of effective vaccines against both FIV and HIV could be established.

Acknowledgements. We are grateful to Dr. Margaret Hosie for her helpful comments on this manuscript.

\section{REFERENCES}

1. Addie D. D., Dennis J. M., Toth S., Callanan J. J., Reid S., and Jarrett O. Long-term impact on a closed household of pet cats of natural infection with feline coronavirus, feline leukaemia virus and feline immunodeficiency virus. Vet. Rec. 2000;146:419-424.

2. Baba T. W., Trichel A. M., An L., Liska V., Martin L. N., Murphey-Corb M., and Ruprecht R. M. Infection and AIDS in adult macaques after nontraumatic oral exposure to cell-free SIV. Science 1996;272:1486-1489.

3. Beatty J. A., Willett B. J., Gault E. A., and Jarrett O. A longitudinal study of feline immunodeficiency virus-specific cytotoxic $\mathrm{T}$ lymphocytes in experimentally infected cats, using antigen-specific induction. J. Virol. 1996;70:6199-6206.

4. Bendinelli M., Pistello M., Del Mauro D., Cammarota G., Maggi F., Leonildi A., Giannecchini S., Bergamini C., and Matteucci D. During readaptation in vivo, a tissue culture-adapted strain of feline immunodeficiency virus reverts to broad neutralization resistance at different times in individual hosts but through changes at the same position of the surface glycoprotein. J. Virol. 2001;75:4584-4593.

5. Bishop S. A., Stokes C. R., Gruffydd-Jones T. J., Whiting C. V., and Harbour D. A. Vaginal and rectal infection of cats with feline immunodeficiency virus. Vet. Microbiol. 1996;51:217-227.

6. Boretti F. S., Leutenegger C. M., Mislin C., Hofmann-Lehmann R., Konig S., Schroff M., Junghans C., Fehr D., Huettner S. W., Habel A., Flynn J. N., Aubert A., Pedersen N. C., Wittig B., and Lutz H. Protection against FIV challenge infection by genetic vaccination using minimalistic DNA constructs for FIV env gene and feline IL-12 expression. AIDS 2000;14:1749-1757.

7. Bucci J. G., English R. V., Jordan H. L., Childers T. A., Tompkins M. B., and Tompkins W. A. Mucosally transmitted feline immunodeficiency virus induces a CD8+ antiviral response that correlates with reduction of cell- associated virus. J. Infect. Dis. 1998;177:18-25.

8. Burkhard M. J., Valenski L., Leavell S., Dean G. A., and Tompkins W. A. Evaluation of FIV protein-expressing VEE-replicon vaccine vectors in cats. Vaccine 2002;21:258268.

9. Chen R., Le Rouzic E., Kearney J. A., Mansky L. M., and Benichou S. Vpr-mediated incorporation of UNG2 into HIV-1 particles is required to modulate the virus mutation rate and for replication in macrophages. J. Biol. Chem. 2004;279:28419-28425.

10. Chiarantini L., Matteucci D., Pistello M., Mancini U., Mazzetti P., Massi C., Giannecchini S., Lonetti I., Magnani M., and Bendinelli M. AIDS vaccination studies using an ex vivo feline immunodeficiency virus model: homologous erythrocytes as a delivery system for preferential immunization with putative protective antigens. Clin. Diagn. Lab. Immunol. 1998;5:235-241.

11. Cuisinier A. M., Mallet V., Meyer A., Caldora C., and Aubert A. DNA vaccination using expression vectors carrying FIV structural genes induces immune response against feline immunodeficiency virus. Vaccine 1997;15:1085-1094. 
12. Cuisinier A. M., Meyer A., Chatrenet B., Verdier A. S., and Aubert A. Attempt to modify the immune response developed against FIV gp120 protein by preliminary FIV DNA injection. Vaccine 1999;17:415-425.

13. Del Mauro D., Matteucci D., Giannecchini S., Maggi F., Pistello M., and Bendinelli M. Autologous and heterologous neutralization analyses of primary feline immunodeficiency virus isolates. J. Virol. 1998;72:2199-2207.

14. Douek D. C., Brenchley J. M., Betts M. R., Ambrozak D. R., Hill B. J., Okamoto Y., Casazza J. P., Kuruppu J., Kunstman K., Wolinsky S., Grossman Z., Dybul M., Oxenius A., Price D. A., Connors M., and Koup R. A. HIV preferentially infects HIV-specific CD4+ T-cells. Nature 2002;417:95-98.

15. Dunham S. P., Bruce J., MacKay S., Golder M. C., Jarrett O., and Neil J. Efficacy of feline immunodeficiency virus vaccines Fel-O-Vax and FIVGL8dIN DNA vaccine: Effect of route of challenge on outcome. Seventh International Feline Retrovirus Research Symposium, Pisa, Italy. 2004.

16. Dunham S. P., Flynn J. N., Rigby M. A., Macdonald J., Bruce J., Cannon C., Golder M. C., Hanlon L., Harbour D. A., Mackay N. A., Spibey N., Jarrett O., and Neil JC. Protection against feline immunodeficiency virus using replication defective proviral DNA vaccines with feline interleukin-12 and -18. Vaccine 2002;20:1483-1496.

17. Fevereiro M., Roneker C., Laufs A., Tavares L., and de Noronha F. Characterization of two monoclonal antibodies against feline immunodeficiency virus gag gene products and their application in an assay to evaluate neutralizing antibody activity. J. Gen. Virol. 1991;72(Pt 3):617-622.

18. Finerty S., Stokes C. R., Gruffydd-Jones T. J., Hillman T. J., Barr F. J., and Harbour D. A. Targeted lymph node immunization can protect cats from a mucosal challenge with feline immunodeficiency virus. Vaccine 2001;20:49-58.

19. Finerty S., Stokes C. R., Gruffydd-Jones T. J., Hillman T. J., Reeves N. A., Whiting C. V., Schaaper W. M., Dalsgaard K., and Harbour D. A. Mucosal immunization with experimental feline immunodeficiency virus (FIV) vaccines induces both antibody and T-cell responses but does not protect against rectal FIV challenge. Vaccine 2000;18:32543265.

20. Flynn J. N., Cannon C. A., Neil J. C., and Jarrett O. Vaccination with a feline immunodeficiency virus multiepitopic peptide induces cell-mediated and humoral immune responses in cats, but does not confer protection. J. Virol. 1997;71:7586-7592.

21. Flynn J. N., Keating P., Hosie M. J., Mackett M., Stephens E. B., Beatty J. A., Neil J. C., and Jarrett O. Env-specific CTL predominate in cats protected from feline immunodeficiency virus infection by vaccination. J. Immunol. 1996;157:3658-3665.

22. Gemeniano M. C., Sawai E. T., and Sparger E. E. Feline immunodeficiency virus Orf-A localizes to the nucleus and induces cell cycle arrest. Virology 2004;325:167-174.

23. Giannecchini S., Isola P., Sichi O., Matteucci D., Pistello M., Zaccaro L., Del Mauro D., and Bendinelli M. AIDS vaccination studies using an ex vivo feline immunodeficiency virus model: failure to protect and possible enhancement of challenge infection by four cell-based vaccines prepared with autologous lymphoblasts. J. Virol. 2002;76:6882-6892.

24. Gonin P., Fournier A., Oualikene W., Moraillon A., and Eloit M. Immunization trial of cats with a replication-defective adenovirus type 5 expressing the ENV gene of feline immunodeficiency virus. Vet. Microbiol. 1995;45:393-401.

25. Hohdatsu T., Pu R., Torres B. A., Trujillo S., Gardner M. B., and Yamamoto J. K. Passive antibody protection of cats against feline immunodeficiency virus infection. J. Virol. 1993;67:2344-2348.

26. Hosie M. J., Dunsford T., Klein D., Willett B. J., Cannon C., Osborne R., Macdonald J., Spibey N., Mackay N., Jarrett O., and Neil J. C. Vaccination with inactivated virus but not viral DNA reduces virus load following challenge with a heterologous and virulent isolate of feline immunodeficiency virus. J. Virol. 2000;74:9403-9411. 
27. Hosie M. J., Dunsford T. H., de Ronde A., Willett B. J., Cannon C. A., Neil J. C., and Jarrett O. Suppression of virus burden by immunization with feline immunodeficiency virus Env protein. Vaccine 1996;14:405-411.

28. Hosie M. J., and Flynn J. N. Feline immunodeficiency virus vaccination: characterization of the immune correlates of protection. J. Virol. 1996;70:7561-7568.

29. Hosie M. J., Flynn J. N., Rigby M. A., Cannon C., Dunsford T., Mackay N. A., Argyle D., Willett B. J., Miyazawa T., Onions D. E., Jarrett O., and Neil J. C. DNA vaccination affords significant protection against feline immunodeficiency virus infection without inducing detectable antiviral antibodies. J. Virol. 1998;72:7310-7319.

30. Hosie, M. J., Klein, D., Binley, J. M., Dunsford, T. H., Jarrett, O., Neil, J. C., Knapp, E., Giannecchini, S., Matteucci, D., Bendinelli, M., Hoxie, J. A., and Willett, B. J. Vaccination with an inactivated virulent feline immunodeficiency virus engineered to express high levels of Env. J. Virol. 2005;79:1954-1957.

31. Hosie M. J., Osborne R., Reid G., Neil J. C., and Jarrett O. Enhancement after feline immunodeficiency virus vaccination. Vet. Immunol. Immunopathol. 1992;35:191-197.

32. Hosie M. J., Osborne R., Yamamoto J. K., Neil J. C., and Jarrett O. Protection against homologous but not heterologous challenge induced by inactivated feline immunodeficiency virus vaccines. J. Virol. 1995;69:1253-1255.

33. Hosie M. J., Willett B. J., Klein D., Dunsford T. H., Cannon C., Shimojima M., Neil J. C., and Jarrett O. Evolution of replication efficiency following infection with a molecularly cloned feline immunodeficiency virus of low virulence. J. Virol. 2002;76:6062-6072.

34. Huisman W., Karlas J. A., Siebelink K. H., Huisman R. C., de Ronde A., Francis M. J., Rimmelzwaan G. F., and Osterhaus A. D. Feline immunodeficiency virus subunit vaccines that induce virus neutralising antibodies but no protection against challenge infection. Vaccine 1998;16:181-187.

35. Huisman W., Schrauwen E. J., Pas S. D., Karlas J. A., Rimmelzwaan G. F., and Osterhaus A. D. Antibodies specific for hypervariable regions 3 to 5 of the feline immunodeficiency virus envelope glycoprotein are not solely responsible for vaccine-induced acceleration of challenge infection in cats. J. Gen. Virol. 2004;85:1833-1841.

36. Inoshima Y., Miyazawa T., Kohmoto M., Ikeda Y., Sato E., Hohdatsu T., Mathiason-Dubard C., Hoover E. A., and Mikami T. Cross virus neutralizing antibodies against feline immunodeficiency virus genotypes A, B, C, D and E. Arch. Virol. 1998;143:157-162.

37. Jordan H. L., Howard J., Barr M. C., Kennedy-Stoskopf S., Levy J. K., and Tompkins W. A. Feline immunodeficiency virus is shed in semen from experimentally and naturally infected cats. AIDS Res. Hum. Retroviruses 1998;14:1087-1092.

38. Karlas J. A., Siebelink K. H., Peer M. A., Huisman W., Cuisinier A. M., Rimmelzwaan G. F., and Osterhaus A. D. Vaccination with experimental feline immunodeficiency virus vaccines, based on autologous infected cells, elicits enhancement of homologous challenge infection. J Gen. Virol. 1999;80:761-765.

39. Lee D., Graham B. S., Chiu Y. L., Gilbert P. B., McElrath M. J., Belshe R. B., Buchbinder S. P., Sheppard H. W., Koblin B. A., Mayer K. H., Keefer M. C., Mulligan M. J., and Celum C. L. Breakthrough infections during phase 1 and 2 prime-boost HIV-1 vaccine trials with canarypox vectors (ALVAC) and booster dose of recombinant gp120 or gp160. J. Infect. Dis. 2004;190:903-907.

40. Lerner D. L., Wagaman P. C., Phillips T. R., Prospero-Garcia O., Henriksen S. J., Fox H. S., Bloom F. E., and Elder J. H. Increased mutation frequency of feline immunodeficiency virus lacking functional deoxyuridine-triphosphatase. Proc. Natl. Acad. Sci. USA. 1995;92:7480-7484.

41. Leutenegger C. M., Boretti F. S., Mislin C. N., Flynn J. N., Schroff M., Habel A., Junghans C., Koenig-Merediz S. A., Sigrist B., Aubert A., Pedersen N. C., Wittig B., and Lutz H. Immunization of cats against feline immunodeficiency virus (FIV) infection by using minimalistic immunogenic defined gene expression vector vaccines expressing FIV gp140 
alone or with feline interleukin-12 (IL-12), IL-16, or a CpG Motif. J. Virol. 2000;74:10447-10457.

42. Leutenegger C. M., Hofmann-Lehmann R., Holznagel E., Cuisinier A. M., Wolfensberger C., Duquesne V., Cronier J., Allenspach K., Aubert A., Ossent P., and Lutz H. Partial protection by vaccination with recombinant feline immunodeficiency virus surface glycoproteins. AIDS Res. Hum. Retroviruses 1998;14:275-283.

43. Lockridge K. M., Chien M., Dean G. A., Stefano C. K., Montelaro R. C., Luciw P. A., and Sparger E. E. Protective immunity against feline immunodeficiency virus induced by inoculation with vif-deleted proviral DNA. Virology 2000;273:67-79.

44. Lombardi S., Garzelli C., Pistello M., Massi C., Matteucci D., Baldinotti F., Cammarota G., Da Prato L., Bandecchi P., and Tozzini F. A neutralizing antibody-inducing peptide of the V3 domain of feline immunodeficiency virus envelope glycoprotein does not induce protective immunity. J. Virol. 1994;68:8374-8379.

45. Malkevitch N. V., and Robert-Guroff M. A call for replicating vector prime-protein boost strategies in HIV vaccine design. Expert. Rev. Vaccines 2004;3:S105-S117.

46. Matteucci D., Baldinotti F., Mazzetti P., Pistello M., Bandecchi P., Ghilarducci R., Poli A., Tozzini F., and Bendinelli M. Detection of feline immunodeficiency virus in saliva and plasma by cultivation and polymerase chain reaction. J. Clin. Microbiol. 1993;31:494501 .

47. Matteucci D., Pistello M., Mazzetti P., Giannecchini S., Del Mauro D., Lonetti I., Zaccaro L., Pollera C., Specter S., and Bendinelli M. Studies of AIDS vaccination using an ex vivo feline immunodeficiency virus model: protection conferred by a fixed-cell vaccine against cell-free and cell-associated challenge differs in duration and is not easily boosted. J. Virol. 1997;71:8368-8376.

48. Matteucci D., Pistello M., Mazzetti P., Giannecchini S., Isola P., Merico A., Zaccaro L., Rizzuti A., and Bendinelli M. AIDS vaccination studies using feline immunodeficiency virus as a model: immunization with inactivated whole virus suppresses viraemia levels following intravaginal challenge with infected cells but not following intravenous challenge with cell-free virus. Vaccine 1999;18:119-130.

49. Matteucci D., Poli A., Mazzetti P., Sozzi S., Bonci F., Isola P., Zaccaro L., Giannecchini S., Calandrella M., Pistello M., Specter S., and Bendinelli M. Immunogenicity of an anti-clade B feline immunodeficiency fixed-cell virus vaccine in field cats. J. Virol. 2000;74:1091110919.

50. Mazzetti P., Giannecchini S., Del Mauro D., Matteucci D., Portincasa P., Merico A., Chezzi C., and Bendinelli M. AIDS vaccination studies using an ex vivo feline immunodeficiency virus model: detailed analysis of the humoral immune response to a protective vaccine. J. Virol. 1999;73:1-10.

51. Moench T. R., Whaley K. J., Mandrell T. D., Bishop B. D., Witt C. J., and Cone R. A. The cat/feline immunodeficiency virus model for transmucosal transmission of AIDS: nonoxynol-9 contraceptive jelly blocks transmission by an infected cell inoculum. AIDS 1993;7:797-802.

52. Osborne R., Rigby M., Siebelink K., Neil J. C., and Jarrett O. Virus neutralization reveals antigenic variation among feline immunodeficiency virus isolates. J. Gen. Virol. 1994;75(Pt 12):3641-3645.

53. Pancino G., and Sonigo P. Retention of viral infectivity after extensive mutation of the highly conserved immunodominant domain of the feline immunodeficiency virus envelope. J. Virol. 1997;71:4339-4346.

54. Pedersen N. C., Ho E. W., Brown M. L., and Yamamoto J. K. Isolation of a T-lymphotropic virus from domestic cats with an immunodeficiency-like syndrome. Science 1987; 235:790-793.

55. Pistello M., Cammarota G., Nicoletti E., Matteucci D., Curcio M., del Mauro D., and Bendinelli M. Analysis of the genetic diversity and phylogenetic relationship of Italian 
isolates of feline immunodeficiency virus indicates a high prevalence and heterogeneity of subtype B. J. Gen. Virol. 1997;78(Pt 9):2247-2257.

56. Pistello M., Matteucci D., Bonci F., Isola P., Mazzetti P., Zaccaro L., Merico A., del Mauro D., Flynn N., and Bendinelli M. AIDS vaccination studies using an ex vivo feline immunodeficiency virus model: protection from an intraclade challenge administered systemically or mucosally by an attenuated vaccine. J. Virol. 2003;77:10740-10750.

57. Pistello M., Matteucci D., Cammarota G., Mazzetti P., Giannecchini S., del Mauro D., Macchi S., Zaccaro L., and Bendinelli M. Kinetics of replication of a partially attenuated virus and of the challenge virus during a three-year intersubtype feline immunodeficiency virus superinfection experiment in cats. J. Virol. 1999;73:1518-1527.

58. Pu R., Coleman J., Coisman J., Sato E., Tanabe T., Arai M., and Yamamoto J. K. Dualsubtype FIV (Fel-O-Vax FIV) protection against heterologous subtype B FIV isolate. $J$. Feline Med. Surg. 7:65-70.

59. Pu R., Coleman J., Omori M., Arai M., Hohdatsu T., Huang C., Tanabe T., and Yamamoto J. K. Dual-subtype FIV vaccine protects cats against in vivo swarms of both homologous and heterologous subtype FIV isolates. AIDS 2001;15:1225-1237.

60. Pu R., Coleman J., and Yamamoto J. K. Dual-subtype FIV vaccine protection against virulent heterologous subtype B virus. Seventh International Feline Retrovirus Research Symposium, Pisa, Italy. 2004.

61. Pu R., Omori M., Okada S., Rine S. L., Lewis B. A., Lipton E., and Yamamoto J. K. MHCrestricted protection of cats against FIV infection by adoptive transfer of immune cells from FIV-vaccinated donors. Cell Immunol. 1999;198:30-43.

62. Reggeti F., and Bienzle D. Feline immunodeficiency virus subtypes A, B and C and intersubtype recombinants in Ontario, Canada. J. Gen. Virol. 2004;85:1843-1852.

63. Richardson J., Broche S., Baud S., Leste-Lasserre T., Femenia F., Levy D., Moraillon A., Pancino G., and Sonigo P. Lymphoid activation: a confounding factor in AIDS vaccine development? J. Gen. Virol. 2002;83:2515-2521.

64. Richardson J., Moraillon A., Baud S., Cuisinier A. M., Sonigo P., and Pancino G. Enhancement of feline immunodeficiency virus (FIV) infection after DNA vaccination with the FIV envelope. J. Virol. 1997;71:9640-9649.

65. Sheehy A. M., Gaddis N. C., and Malim M. H. The antiretroviral enzyme APOBEC3G is degraded by the proteasome in response to HIV-1 Vif. Nat. Med. 2003;9:1404-1407.

66. Shimojima M., Miyazawa T., Ikeda Y., McMonagle E. L., Haining H., Akashi H., Takeuchi Y., Hosie M. J., and Willett B. J. Use of CD134 as a primary receptor by the feline immunodeficiency virus. Science 2004;303:1192-1195.

67. Siebelink K. H., Tijhaar E., Huisman R. C., Huisman W., de Ronde A., Darby I. H., Francis M. J., Rimmelzwaan G. F., and Osterhaus A. D. Enhancement of feline immunodeficiency virus infection after immunization with envelope glycoprotein subunit vaccines. J. Virol. 1995;69:3704-3711.

68. Sodora D. L., Gettie A., Miller C. J., and Marx P. A. Vaginal transmission of SIV: assessing infectivity and hormonal influences in macaques inoculated with cell-free and cellassociated viral stocks. AIDS Res. Hum. Retroviruses 1998;14(Suppl 1):S119-S123.

69. Steinrigl A., and Klein D. Phylogenetic analysis of feline immunodeficiency virus in Central Europe: a prerequisite for vaccination and molecular diagnostics. J. Gen. Virol. 2003;84:1301-1307.

70. Stevens R., Howard K. E., Nordone S., Burkhard M., and Dean G. A. Oral immunization with recombinant Listeria monocytogenes controls virus load after vaginal challenge with feline immunodeficiency virus. J. Virol. 2004;78:8210-8218.

71. Tellier M. C., Pu R., Pollock D., Vitsky A., Tartaglia J., Paoletti E., and Yamamoto J. K. Efficacy evaluation of prime-boost protocol: canarypoxvirus-based feline immunodeficiency virus (FIV) vaccine and inactivated FIV- infected cell vaccine against heterologous FIV challenge in cats. AIDS 1998;12:11-18. 
72. Tijhaar E. J., Huisman W., Huisman R. C., Siebelink K. H., Karlas J. A., de Ronde A., van Herwijnen R., Mooi F. R., and Osterhaus A. D. Salmonella typhimurium aroA recombinants and immune-stimulating complexes as vaccine candidates for feline immunodeficiency virus. J. Gen. Virol. 1997;78(Pt 12):3265-3275.

73. Tijhaar E. J., Siebelink K. H., Karlas J. A., Burger M. C., Mooi F. R., and Osterhaus A. D. Induction of feline immunodeficiency virus specific antibodies in cats with an attenuated Salmonella strain expressing the Gag protein. Vaccine 1997;15:587-596.

74. Veazey R., and Lackner A. The mucosal immune system and HIV-1 infection. AIDS Rev. 2003;5:245-252.

75. Verschoor E. J., van Vliet A. L., Egberink H. F., Hesselink W., van Alphen W. E., Joosten I., Boog C. J., Horzinek M. C., and de Ronde A. Vaccination against feline immunodeficiency virus using fixed infected cells. Vet. Immunol. Immunopathol. 1995;46:139-149.

76. Whitney J. B., and Ruprecht R. M. Live attenuated HIV vaccines: pitfalls and prospects. Curr. Opin. Infect. Dis. 2004;17:17-26.

77. Willett B. J., Hosie M. J., Callanan J. J., Neil J. C., and Jarrett O. Infection with feline immunodeficiency virus is followed by the rapid expansion of a CD8+ lymphocyte subset. Immunology 1993;78:1-6.

78. Willett B. J., Hosie M. J., Neil J. C., Turner J. D., and Hoxie J. A. Common mechanism of infection by lentiviruses [letter]. Nature 1997;385:587.

79. Willett B. J., Picard L., Hosie M. J., Turner J. D., Adema K., and Clapham P. R. Shared usage of the chemokine receptor CXCR4 by the feline and human immunodeficiency viruses. J. Virol. 1997;71:6407-6415.

80. Willey R. L., Byrum R., Piatak M., Kim Y. B., Cho M. W., Rossio J. J., Jr., Bess J. J., Jr., Igarashi T., Endo Y., Arthur L. O., Lifson J. D., and Martin M. A. Control of viremia and prevention of simian-human immunodeficiency virus-induced disease in rhesus macaques immunized with recombinant vaccinia viruses plus inactivated simian immunodeficiency virus and human immunodeficiency virus type 1 particles. J. Virol. 2003;77:1163-1174.

81. Yamamoto J. K., Hohdatsu T., Olmsted R. A., Pu R., Louie H., Zochlinski H. A., Acevedo V., Johnson H. M., Soulds G. A., and Gardner M. B. Experimental vaccine protection against homologous and heterologous strains of feline immunodeficiency virus. J. Virol. 1993;67:601-605.

82. Yamamoto J. K., Okuda T., Ackley C. D., Louie H., Pembroke E., Zochlinski H., Munn R. J., and Gardner M. B. Experimental vaccine protection against feline immunodeficiency virus. AIDS Res. Hum. Retroviruses 1991;7:911-922. 